OPEN ACCESS

Edited by:

Ai-Ling Lin,

University of Kentucky, United States

Reviewed by:

Olivier Thibault,

University of Kentucky, United States William Sonntag,

University of Oklahoma Health

Sciences Center, United States

Sreemathi Logan contributed to the review of William Sonntag

*Correspondence:

Bryan J. Neth

bneth@wakehealth.edu

Received: 07 September 2017 Accepted: 13 October 2017

Published: 31 October 2017

Citation:

Neth BJ and Craft S (2017) Insulin Resistance and Alzheimer's Disease:

Bioenergetic Linkages.

Front. Aging Neurosci. 9:345.

doi: 10.3389/fnagi.2017.00345

\section{Insulin Resistance and Alzheimer's Disease: Bioenergetic Linkages}

\author{
Bryan J. Neth* and Suzanne Craft
}

Department of Internal Medicine, Section on Gerontology and Geriatric Medicine, Wake Forest School of Medicine, Winston-Salem, NC, United States

Metabolic dysfunction is a well-established feature of Alzheimer's disease (AD), evidenced by brain glucose hypometabolism that can be observed potentially decades prior to the development of $A D$ symptoms. Furthermore, there is mounting support for an association between metabolic disease and the development of $A D$ and related dementias. Individuals with insulin resistance, type 2 diabetes mellitus (T2D), hyperlipidemia, obesity, or other metabolic disease may have increased risk for the development of $A D$ and similar conditions, such as vascular dementia. This association may in part be due to the systemic mitochondrial dysfunction that is common to these pathologies. Accumulating evidence suggests that mitochondrial dysfunction is a significant feature of $A D$ and may play a fundamental role in its pathogenesis. In fact, aging itself presents a unique challenge due to inherent mitochondrial dysfunction and prevalence of chronic metabolic disease. Despite the progress made in understanding the pathogenesis of $A D$ and in the development of potential therapies, at present we remain without a disease-modifying treatment. In this review, we will discuss insulin resistance as a contributing factor to the pathogenesis of $A D$, as well as the metabolic and bioenergetic disruptions linking insulin resistance and AD. We will also focus on potential neuroimaging tools for the study of the metabolic dysfunction commonly seen in $\mathrm{AD}$ with hopes of developing therapeutic and preventative targets.

Keywords: Alzheimer's disease, insulin resistance, bioenergetic shift, ketone body, inflammation, metabolism, positron emission tomography

\section{INTRODUCTION AND OVERVIEW}

Alzheimer's disease (AD) is a fatal neurodegenerative disorder that afflicts an estimated 5.3 million people in the United States. Due to socioeconomic forces such as an aging population, the prevalence of $\mathrm{AD}$ is projected to nearly triple to about 13.8 million Americans at an annual cost of greater than $\$ 1$ trillion by 2050 (Alzheimer's Association, 2015). AD consists of two forms; familial or early-onset $\mathrm{AD}(\mathrm{FAD})$, which constitutes less than $5 \%$ of all $\mathrm{AD}$ cases and is normally diagnosed prior to the age of 65 years, with clear genetic risk through inherited mutations in three main genes: amyloid precursor protein (APP), presenilin 1 (PSEN1) and presenilin 2 (PSEN2; Selkoe, 1996). Sporadic or late-onset-AD (LOAD) makes up the great majority of all AD cases and is usually diagnosed after the age of 65 years. The most prominent risk factor for the development of LOAD is advanced age and indeed the incidence of $\mathrm{AD}$ increases with advancing age. 
Although several genetic risk factors for LOAD have been identified, the most significant of these is the Apolipoprotein-Eepsilon-4 allele (APOE4), which is an isoform of the APOE gene that plays a role in cholesterol and beta-amyloid peptide $(\mathrm{A} \beta)$ homeostasis (Genin et al., 2011; Karch et al., 2012; Alzheimer's Association, 2015).

$\mathrm{AD}$ is characterized by a progressive deterioration in cognition with significant impairments in memory, executive function and behavioral/personality changes. Neuropathologic hallmarks of $\mathrm{AD}$ include neuritic plaques and neurofibrillary tangles that are initially seen in the medial temporal lobes and eventually extend throughout the cortex (Braak and Braak, 1991; Braak et al., 2006). Additional misfolded proteins, including TAR DNA binding protein 43 (TDP-43) positive inclusions may be found in brains of individuals with $\mathrm{AD}$ (AmadorOrtiz et al., 2007). The leading hypothesis concerning the pathogenesis of $\mathrm{AD}$ is the Amyloid Cascade Hypothesis, which postulates that $\mathrm{A} \beta$ plays a central role in $\mathrm{AD}$ pathology leading to oxidative injury, synaptic/neuronal dysfunction and eventual neurodegeneration (Hardy and Higgins, 1992; Hardy and Selkoe, 2002). The clinical path of AD may be viewed as a continuum with an extended asymptomatic stage without cognitive or behavioral symptoms, but with documentable changes in brain pathological processes-with ultimate progression to mild cognitive impairment (MCI) and eventually dementia with cognitive and functional decline (Sperling et al., 2011).

Central metabolic dysfunction is a well-established feature of $\mathrm{AD}$, evidenced by brain glucose hypometabolism that can be observed potentially decades prior to the development of AD symptoms (Reiman et al., 1996; Small et al., 2000; Sperling et al., 2011). Furthermore, there is mounting support for an association between metabolic disease and the development of $\mathrm{AD}$ and related dementias (Whitmer et al., 2008; Craft, 2009). Individuals with insulin resistance, type 2 diabetes mellitus (T2D), hyperlipidemia, obesity, or other metabolic disease may have increased risk for the development of $\mathrm{AD}$ and similar conditions, such as vascular dementia (Craft, 2009; Di Paolo and Kim, 2011). This association may in part be due to the systemic mitochondrial dysfunction that is common to these pathologies (Lesnefsky et al., 2001; Lowell and Shulman, 2005; Madamanchi and Runge, 2007; Johri and Beal, 2012). Accumulating evidence suggests that mitochondrial dysfunction is a significant feature of $\mathrm{AD}$ and may play a fundamental role in its pathogenesis (Yao et al., 2010; Yao and Brinton, 2011; Chaturvedi and Beal, 2013). In fact, aging itself presents a unique challenge due to inherent mitochondrial dysfunction and prevalence of chronic metabolic disease (Mammucari and Rizzuto, 2010; Cui et al., 2012).

Despite the progress made in understanding the pathogenesis of $\mathrm{AD}$ and in the development of potential therapies, at present we remain without a disease-modifying treatment (Armstrong, 2011; Schneider et al., 2011a,b; Howard et al., 2012; Doody et al., 2014; Salloway et al., 2014). In this review, we will discuss insulin resistance as a contributing factor to the pathogenesis of $\mathrm{AD}$, as well as the metabolic and bioenergetic disruptions linking insulin resistance and $\mathrm{AD}$. We will close with a review of potential tools for the study of the metabolic dysfunction commonly seen in $\mathrm{AD}$.

\section{METABOLIC PATHWAYS TO ALZHEIMER'S DISEASE: INSULIN RESISTANCE}

\section{Overview of Insulin in the Brain}

Insulin is a peptide hormone secreted principally by pancreatic beta cells with well-characterized functions in glucose/lipid metabolism, vascular regulation, and cell growth (Saltiel and Kahn, 2001; Muniyappa et al., 2007). Mounting evidence suggests that insulin plays a vital role in the central nervous system (CNS; Craft and Watson, 2004; Ketterer et al., 2011; Liu et al., 2011; Banks et al., 2012; Correia et al., 2012; Duarte et al., 2012; Cholerton et al., 2013; Craft et al., 2013; Blázquez et al., 2014). Insulin readily crosses the Blood Brain Barrier (BBB) through a saturable, receptor-mediated process (Baskin et al., 1987; Baura et al., 1993; Banks et al., 1997a,b; Woods et al., 2003). Moreover, several regions in the brain (hypothalamus, choroid plexus, etc.) may serve as a more rapid site of entry for peripheral insulin into the CNS (Baskin et al., 1987). There is continuing debate concerning production of insulin within CNS. Studies in animal models have described presence of insulin mRNA in various brain regions (Banks et al., 2012; Duarte et al., 2012). Clinical studies have described the presence of C-peptide, which is secreted at the time of insulin production in pancreatic beta cells, in cerebrospinal fluid (CSF; Ghasemi et al., 2013b; Blázquez et al., 2014). However, this too may be from the pancreas and not produced within the CNS.

Insulin exerts its action through binding to the insulin receptor (IR) with two different isoforms (IR-A and IR-B). IR-A is found in the adult nervous system and has a higher affinity for insulin than IR-B, which is found mainly is adipose tissue, hepatic tissue, and skeletal muscle (Zhao W.-Q. et al., 2004; Dou et al., 2005; Watson and Craft, 2006; Banks et al., 2012; Ghasemi et al., 2013b). However, a recent study has reported IR-B expression in astrocytes (Garwood et al., 2015), with a potential role in mediating insulin and insulin-like growth factor (IGF) function in the CNS. It is important to note that insulin-like growth factor-1 and 2 (IGF-1, IGF-2) can also bind at the IR, but at decreased affinity than insulin (Banks et al., 2012; Kleinridders et al., 2014). IRs are tyrosine kinases with alpha and beta subunits. Once insulin or other substrates are bound, the alpha subunit promotes autophosphorylation of tyrosine residues on the beta subunits leading to the recruitment of scaffolding proteins, mainly IR substrates 1 and 2 (IRS- 1 and IRS-2). IRS-1, 2 ultimately connect insulin to two significant signal transduction pathways: the PI3K/Akt pathway, largely responsible for metabolic effects, lipid/protein synthesis and the Ras/ERK pathway which modulates cell growth, survival, and gene expression (De Felice and Ferreira, 2014; Kleinridders et al., 2014). IRs are located in both neurons and glia (Abbott et al., 1999). These receptors are selectively distributed throughout the brain, with higher concentrations in the 
olfactory bulb, cerebral cortex, hippocampus, hypothalamus, amygdala, and septum-regions of strategic importance for feeding and cognition (Havrankova et al., 1978a,b; Baskin et al., 1987; Unger et al., 1991). Similar to IR, IGF-1 receptors (IGF1-R) are also tyrosine kinases binding IGF$1 / 2$ and insulin. Interestingly, both IR and IGF1-R can form hybrids of either heterodimers or homodimers with each other. The ultimate downstream effects depend on the ligand and type/location of receptor. Likewise, the affinity of the ligand also depends on the receptor type. The distribution of IR, IGF1-R, and their hybrids are regionally specific within the CNS (Kleinridders, 2016; Cai et al., 2017). Refer to a recent review by Kleinridders (2016) for a more comprehensive understanding of IR and IGF-1 receptors in the brain.

\section{Insulin and Cognition}

An acute elevation of peripheral insulin (generally in response to an increase in exogenous or endogenous glucose) promotes insulin transport across the BBB into the CNS, thus facilitating its role for a variety of important brain functions (Woods et al., 2003; Kleinridders et al., 2014). The regional localization of IR in the hippocampus (Werther et al., 1987) suggests that insulin may influence memory, one of the main tasks supported by the hippocampus and closely connected structures. Intracerebroventricular administration of insulin in rats has been shown to improve passive avoidance and spatial memory (Park et al., 2000; Haj-ali et al., 2009). Clinical studies utilizing acute intravenous administration of insulin with maintenance of euglycemia have described enhanced performance in verbal memory (Craft et al., 1996, 1999, 2003; Kern et al., 2001). Similar memory improvement has been observed following administration of intranasal insulin (Benedict et al., 2004, 2008; Stockhorst et al., 2004; Reger et al., 2006, 2008; Craft et al., 2012; Schiöth et al., 2012; Claxton et al., 2013, 2015; Freiherr et al., 2013; Novak et al., 2014); these studies will be reviewed in detail below. In total, the above work forms a strong foundation for insulin's role in memory, one of the key cognitive domains affected by AD.

Intriguingly, the process of learning may modify IR expression and function throughout specific brain regions (Zhao et al., 1999; Zhao W.-Q. et al., 2004; Agrawal et al., 2011). In rats, spatial memory training has been shown to upregulate IR mRNA in the hippocampal CA1 region and dentate gyrus and lead to increased accumulation of IR protein within the hippocampus. Moreover, training increased insulin-stimulated tyrosine phosphorylation of the IR in vitro in trained animals (Zhao et al., 1999). These results suggest that learning itself may influence both IR concentration and insulin signaling in the hippocampus and potentially other brain regions. It is likely that insulin plays a key role in learning and memory given IR localization in the hippocampus, IR changes in the hippocampus secondary to spatial learning, and improvements in memory secondary to insulin administration in both animal models and human studies. Although it is not entirely clear how insulin exerts its action on cognition, several mechanisms likely contribute.

\section{Insulin and Cerebral Glucose Metabolism}

One such mechanism by which insulin may influence cognition is by affecting cerebral energy metabolism. The importance of glucose in the CNS is demonstrated by the disproportionate metabolic rate of the brain relative most organs and tissues. While the brain only makes up $2 \%$ of the average body weight, it utilizes about $25 \%$ of the body's glucose and $20 \%$ of the body's oxygen to meet metabolic demand (Attwell and Laughlin, 2001; Bélanger et al., 2011). The energy derived from glucose metabolism is used to maintain neuronal ion gradients and cell membrane lipid remodeling, among other processes (Attwell and Laughlin, 2001). Insulin undoubtedly is crucial for peripheral energy metabolism in adipose tissue, hepatic tissue, and skeletal muscle (Saltiel and Kahn, 2001). Until recently brain (glucose) metabolism has largely been thought of as insulin-independent. Yet, recent research has highlighted an important role of insulin in cerebral/peripheral metabolism and other functions (Banks et al., 2012; Blázquez et al., 2014).

Bingham et al. (2002) reported increased cerebral glucose metabolism after restoration of basal levels of insulin in metabolically healthy participants. Metabolic changes were most apparent in cortical areas. This work indicates that normal basal levels of peripheral insulin may play an important role in the maintenance of cerebral glucose metabolism. In a recent study of adults with metabolic dysfunction, Hirvonen et al. (2011) reported increased glucose metabolism on ${ }^{18}$ F-fluorodeoxyglucose (FDG) Positron Emission Tomography (PET) imaging after a hyperinsulinemic clamp procedure. Interestingly, glucose metabolism was not affected by the hyperinsulinemic condition in metabolically healthy participants (Hirvonen et al., 2011). These results support the view that insulin may modify cerebral glucose metabolism, and that effects may differ depending upon metabolic status.

Insulin likely exerts regional effects on cerebral glucose metabolism due to the localized distribution of glucose transporters (GLUTs; Schulingkamp et al., 2000; Reagan et al., 2001). A recent review by Shah et al. (2012) discusses the role of these transporters in brain disease, with a focus on $\mathrm{AD}$ and diabetes. The insulin independent GLUT1 and GLUT3 were traditionally believed to be the sole cerebral GLUTs (LundAndersen, 1979). These GLUTs are expressed at the BBB and within neurons and glia (Devraj et al., 2011; Shah et al., 2012). However, it is now apparent that insulin-responsive GLUTs, such as GLUT4 and GLUT8, are also localized within specific brain regions such as the hippocampus, cerebellum, sensorimotor cortex, hypothalamus and pituitary (Brant et al., 1993; Livingstone et al., 1995; El Messari et al., 1998; Apelt et al., 1999; Reagan et al., 2001; Shah et al., 2012). Insulin has been reported to increase cerebral GLUT4 expression and translocation (Piroli et al., 2007). Importantly, insulin-responsive GLUT4 and GLUT8 are co-localized to regions that express IR and insulin (Apelt et al., 1999; Schulingkamp et al., 2000). Our understanding of cerebral glucose metabolism continues to expand, with new insights supporting the role of insulin in mediating at least some portion of cerebral glucose metabolism, which likely impacts cognitive processes including learning and memory. 


\section{Other Actions}

In addition to insulin's function in cerebral glucose metabolism, another mechanism by which it may impact the brain is its influence on long-term potentiation (LTP; Zhao and Alkon, 2001). In particular, insulin has been reported to affect the expression of $\mathrm{N}$-methyl-D-aspartate (NMDA) receptors (Skeberdis et al., 2001). Furthermore, insulin has been shown to modulate levels of the neurotransmitters, acetylcholine and norepinephrine, which have been shown to influence cognition (Figlewicz et al., 1993; Kopf and Baratti, 1999). Insulin also serves other important functions through actions in the brain such as neuroprotective effects as well as mediation of vascular function through nitric oxide (NO) and endothelin-1 (Banks et al., 2012; Katakam et al., 2012; Blázquez et al., 2014). The importance of insulin's role in the CNS is becoming increasingly clear as converging evidence demonstrates that disrupted insulin signaling (insulin resistance) may promote neurodegenerative disorders, such as AD (Craft, 2007, 2009; Neumann et al., 2008; Cholerton et al., 2011; Correia et al., 2012; Chen and Zhong, 2013; Ghasemi et al., 2013b; Blázquez et al., 2014; De Felice and Ferreira, 2014; Sridhar et al., 2015).

\section{Overview of Insulin Resistance}

Insulin resistance occurs when insulin binding to its receptors has diminished effects. Although this term is most commonly applied to decreased glucose clearance from the blood and entry into target tissues (Reaven, 1983, 2003; DeFronzo et al., 1992), it can also refer to insulin's ability to engage its canonical signaling network in any target tissue. In the periphery this resistance is accompanied by increased release of insulin from the pancreas to meet the demand of chronically elevated levels of glucose and/or increased amount of adipose tissue that requires insulin for its glucose metabolism (DeFronzo et al., 1992). Prolonged elevation of systemic insulin may ultimately lead to a dysfunction in insulin signaling (DeFronzo, 2010). This chronic elevation in peripheral insulin levels also impacts central insulin availability and function. Insulin's passage through the $\mathrm{BBB}$ is transporter-mediated (Banks et al., 2012). In a healthy state, an acute, transient rise in peripheral insulin leads to an increase in CNS insulin, where it enters the brain. Chronic peripheral hyperinsulinemia leads to the downregulation of insulin transporters at the $\mathrm{BBB}$, which in turn decreases the amount of insulin that may enter brain (Wallum et al., 1987; Schwartz et al., 1990; Banks et al., 2012). This CNS insulin deficiency may potentially lead to impairments in memory, neuroprotective effects, synaptic transmission, as well as likely contributing to the development of neurodegenerative disease (Craft and Watson, 2004; Craft, 2007; Cholerton et al., 2011; Correia et al., 2012; Ghasemi et al., 2013a; Blázquez et al., 2014; De Felice and Ferreira, 2014; De Felice and Lourenco, 2015). Importantly, negative impacts of insulin resistance occur years prior to the development of clinically defined diabetes (Roriz-Filho et al., 2009). Early defects in insulin signaling may be associated with pathologic brain changes even decades before clinical symptoms of the disease (Roriz-Filho et al., 2009). Moreover, patients may not appreciate significant symptoms until the disease process has already exerted a negative, and potentially irreversible impact on peripheral tissues and the brain (Sperling et al., 2011; Sridhar et al., 2015).

\section{Impact of Insulin Resistance on the Brain}

In a metabolically healthy state, an acute elevation of insulin levels has a beneficial impact on cognitive function. However, chronically elevated insulin greatly diminishes insulin's end-organ effects (Neumann et al., 2008). Evidence supporting this include impaired learning in animal models of T2D and in humans with the disorder (Greenwood and Winocur, 2001). Vanhanen et al. (1998) described lower scores on the Bushcke Selective Reminding Task (verbal learning and memory) in older adults with impaired glucose tolerance. Insulin resistance also impacts brain structure and function corresponding with changes in brain volumes and cerebral glucose metabolism. Convit et al. (2003) described lower hippocampal volumes in older adults with impaired glucose tolerance, which were also associated with lower scores on delayed recall of a logical memory task. Similarly, a study by Kerti et al. (2013) reported that adults with higher fasting glucose and HbAlc had lower delayed recall, learning, and memory consolidation utilizing the Rey Auditory Verbal Learning Test. Higher fasting glucose and $\mathrm{HbA1c}$ also correlated with lower hippocampal volume and altered hippocampal microstructure as determined by Mean Diffusivity, a Diffusion Tensor Imaging (DTI) metric (Kerti et al., 2013). Further analysis in this group suggested that the beneficial effects of lower blood glucose on learning and memory could in part be explained by the hippocampal changes described in the study (Kerti et al., 2013). Moreover, we have previously reported that older adults with insulin resistance (pre-diabetes or diabetes without treatment) showed AD-like patterns of reduced brain glucose metabolism, as quantified with FDG PET imaging. Glucose hypometabolism was most apparent in frontal, parietotemporal, and cingulate cortices (Baker et al., 2011). This finding is profound in that it provides evidence that insulin resistance affects similar brain areas as $\mathrm{AD}$, supporting the view that insulin resistance may promote neurodegenerative disease. Diabetes has been shown to be a strong predictor of cognitive decline in older adults (Yaffe et al., 2004, 2006; Cheng et al., 2012; Biessels et al., 2014). In fact, those with diabetes may be twice as likely to experience a decline in cognition over 5 years relative to those without the disorder (Tilvis et al., 2004). Likewise, several epidemiologic studies have described an association between insulin resistance and cognitive impairment and/or the development of dementia in older adults (Hassing et al., 2004; Yaffe et al., 2004; Strachan, 2011; Cheng et al., 2012). Cognitive impairment is not restricted to changes in learning and memory, but also other domains. For example, Abbatecola et al. (2004) showed that insulin resistance was associated with longer time to complete Trail Making Test-Part B. The Trail Making Test is a task of processing speed, cognitive flexibility and visual motor skills and has sensitivity for a variety of disorders negatively affecting cognition (Bowie and Harvey, 2006). Given current evidence insulin resistance 
must be considered an important risk factor for cognitive decline.

Research in humans is largely supported by work in animal models of insulin resistance, describing its negative impact on cognitive performance. Stranahan et al. (2008) demonstrated that a high-saturated fat diet supplemented with high fructose corn syrup-laden water, as a proxy for a "Western Diet," led to worse performance on a spatial memory (water-maze) task relative to control animals and reduced LTP after 8 months on diet. Rats on a high saturated fat diet developed insulin resistance, which was accompanied by lower concentrations of hippocampal brainderived neurotrophic factor (BDNF; Stranahan et al., 2008). These results provide evidence supporting the profound impact that insulin resistance may have on the mammalian brain, an in particular on the hippocampus, one of the primary brain regions implicated in AD pathology.

In summary, work in both humans and animal models suggest that insulin resistance has detrimental effects on cognition, most notably learning and memory. Given the vital influence of insulin resistance on brain, it is important to further understand the metabolic pathways that may be impacted in such conditions, as well as how these pathways related to $\mathrm{AD}$ and other neurodegenerative disorders.

\section{BIOENERGETIC DISRUPTIONS IN INSULIN RESISTANT STATE RELEVANT TO ALZHEIMER'S DISEASE}

Although the pathogenesis of insulin resistance and $\mathrm{AD}$ are yet to be fully elucidated, both share common pathologic features, supporting the notion that systemic insulin resistance may ultimately promote $\mathrm{AD}$. Common features of an insulin resistant state and $\mathrm{AD}$ include inflammation, dyslipidemia, amyloidogenesis and overt bioenergetic dysfunction.

\section{Inflammation and Vascular Dysfunction}

Chronic inflammation is detrimental to the body and brain (Blasko et al., 2004; Khansari et al., 2009; Schwartz and Baruch, 2014), with elevated levels of inflammatory cytokines and chemokines reported in $\mathrm{AD}$ and insulin resistance (Blum-Degen et al., 1995; Pradhan et al., 2001; Kubaszek et al., 2003; Swardfager et al., 2010). Not surprisingly, chronic low-level inflammation in adipose tissue has been hypothesized to contribute to the pathogenesis of insulin resistance (Festa et al., 2000; Akash et al., 2013). A type of inflammatory cell, the adipose tissue macrophage, may be a central player in perpetuating the inflammatory cascade that ultimately leads to insulin resistance and T2D (Lee, 2013). Inflammation has been a feature commonly identified in studies of $\mathrm{AD}$ and other neurodegenerative disorders (Akiyama et al., 2000; Amor et al., 2010; WyssCoray and Rogers, 2012). Inflammatory cytokines are commonly elevated in the plasma and CSF of Alzheimer's patients (BlumDegen et al., 1995; Swardfager et al., 2010). Furthermore, research has explored the role of other inflammatory mediators in $\mathrm{AD}$ with focus on BBB and vascular integrity (Ryu and McLarnon, 2009; Takeda et al., 2013).
A powerful mediator of inflammation and vascular dysfunction common to both insulin resistance and $\mathrm{AD}$ are advanced glycation end products (AGEs), which are glycated proteins and lipids formed through non-enzymatic glycosylation after exposure to glucose (Singh et al., 2001). There are increased AGEs in adults with insulin resistance and diabetes relative to healthy controls (Goldin et al., 2006; Unoki et al., 2007; Unoki and Yamagishi, 2008; Yamagishi et al., 2012). Accumulation of AGEs may exert negative effects on tissues. For example, AGE binding to its target, the receptor for advanced glycation end products (RAGE), promotes upregulation of nuclear factor-

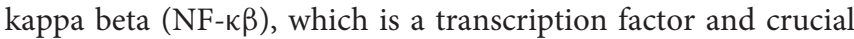
mediator of inflammation (Goldin et al., 2006). AGEs may block the production of $\mathrm{NO}$ in the endothelium, thereby mitigating its vasodilatory effects. Moreover, a complex of AGE-RAGE may interfere with vascular structure, making it permeable to macromolecule invasion and resultant pathology (Goldin et al., 2006). Wautier et al. (1996) reported that inhibition of RAGE prevents the AGE-related changes in vascular permeability within diabetic rats. This research suggests that a prominent feature in individuals with insulin resistance (AGE) may propagate an inflammatory cascade and vascular injury. AGEs are also more elevated in adults with $\mathrm{AD}$ than age-matched controls and may ultimately contribute to $\mathrm{AD}$ pathology (Sasaki et al., 1998; Srikanth et al., 2011). AGEs have been discovered in amyloid-containing senile plaques, tau-containing neurofibrillary tangles, neurons and glia (Lüth et al., 2005). Glycation of $\mathrm{A} \beta$ has been shown to enhance its aggregation (Sasaki et al., 1998) AGEs have been reported to stimulate tau hyperphosphorylation, which is attenuated with inhibition of RAGE in rats (Lüth et al., 2005). Moreover, AGEs stimulate similar oxidative stress, inflammation, and vascular pathology in the brain as that found in the periphery (Ramasamy et al., 2005).

\section{Dyslipidemia}

Insulin is an important mediator of lipid metabolism, and a core feature of insulin resistance is dyslipidemia (DeFronzo and Ferrannini, 1991; Savage et al., 2007). Lipids and cholesterol constitute a significant portion of the brain mass, with continual turnover, especially at synapses and cellular connections (Robinson et al., 1992; Purdon et al., 2002). Impaired lipid metabolism may therefore have a profound impact on the brain and contribute to neurologic disease. The characteristic lipid profile of chronic insulin resistance includes elevated free fatty acids (FFA), which inhibit the insulin-related suppression of very low density lipoprotein (VLDL) secretion by the liver (DeFronzo and Ferrannini, 1991). This contributes to an altered lipid balance with elevated VLDL and other lipids, which may perpetuate an insulin resistant state (DeFronzo and Ferrannini, 1991; Kamagate et al., 2008). Higher low density lipoprotein (LDL) and lower high density lipoprotein (HDL) levels are known cardiovascular risk factors, and could play a role in development of $\mathrm{AD}$-related amyloid deposition, potentially due to the impact of cholesterol on A $\beta$ processing within the brain (Reitz, 2013; Berti et al., 2015). 
Furthermore, various genetic studies including genome-wide association studies (GWAS) have identified several genes involved with lipid and cholesterol metabolism as increasing risk for AD. Most notably is Apolipoprotein-E (APOE), followed by Apolipoprotein-J (APOJ or Clusterin, CLU), ATP-binding cassette subfamily A member 7 (ABCA7) and sortilin-like receptor (SORL1; Reitz, 2013). Although our understanding of dyslipidemia, cholesterol metabolism and its relation to AD is incomplete, it seems plausible that altered states of systemic lipid metabolism may contribute to pathologic brain changes seen in the disease. A study by Reed et al. (2014) reported that higher levels of LDL and lower levels of HDL were associated with higher amount of amyloid concentration as determined by Pittsburgh Compound $\mathrm{B}(\mathrm{PiB})$ PET imaging. These results suggest a potential association between dyslipidemia and cardiovascular risk and the accumulation of cerebral amyloid, which may in turn be mediated by insulin resistance as well as other causes of disturbed lipid metabolism, such as carriage of the APOE4 allele. Intriguingly, a recent study suggests that carriage of an APOE4 allele may contribute to diminished IR signaling by directly interacting with the IR, impairing its trafficking and ultimately leading to the IR being trapped within endosomes (Zhao et al., 2017). This may provide novel insight into the role of APOE and its relation to insulin signaling, thus explaining the differential response to intranasal insulin in APOE4 carriers (Reger et al., 2006; Claxton et al., 2013, 2015).

\section{Amyloidogenesis}

Both $\mathrm{AD}$ and $\mathrm{T} 2 \mathrm{D}$ are amyloidogenic conditions; $\mathrm{A} \beta$ (1-40 and 1-42) is found at increased concentrations in $\mathrm{AD}$ and amylin (islet amyloid polypeptide, IAPP) is found at elevated levels within insulin resistant states (Cooper et al., 1989; Hardy and Higgins, 1992; Lim et al., 2010). Amylin accumulates primarily in the pancreas, which may potentiate the development of T2D and worsening insulin resistance as pancreatic beta cells become depleted (Cooper et al., 1989; Jackson et al., 2013). Recent studies have also described amylin accumulation in other tissues throughout the body, including in cerebral vasculature and brain parenchyma (Despa et al., 2012; Jackson et al., 2013; Srodulski et al., 2014). Jackson et al. (2013) described the accumulation of oligomeric amylin and amylin plaques in the temporal lobes, vasculature and perivascular spaces of older adults with T2D, but not in age-matched controls. A similar pattern of amylin deposition was found in the cerebral vessels and brain parenchyma of adults with $\mathrm{AD}$, even in the absence of T2D. Co-localized amylin and $\mathrm{A} \beta$ deposition were also observed (Jackson et al., 2013). These results suggest that amylin may have a pathologic impact on the brain and contribute to metabolic risk for AD. It is becoming increasingly clear that the amylin and $A \beta$ may not be mutually exclusive. Research suggests that amylin may indeed contribute to the accumulation of $\mathrm{A} \beta$ in $\mathrm{AD}$ through seeding effects (Yan et al., 2014; Oskarsson et al., 2015). Yet, further research into this $\mathrm{A} \beta$-amylin interaction must be performed in order to fully understand the molecular link between these two amyloidogenic molecules.
Furthermore, insulin has been shown to impact $A \beta$, which has traditionally been implicated in the pathogenesis of $\mathrm{AD}$ (Hardy and Higgins, 1992; Hardy and Selkoe, 2002). Evidence in animal models suggests that brain insulin deficiency may lead to increased formation of A $\beta$ due to the upregulation of APP and beta-secretase 1 (BACE1), which are involved in formation of $\mathrm{A} \beta$ (Devi et al., 2012). In vitro studies have reported that insulin impacts amount of $A \beta$. For example, in neuronal cultures insulin stimulates the release of intracellular $A \beta$ (1-40 and 1-42) into the extracellular space. Trafficking of intracellular A $\beta$ and APP is accelerated as they are transported from the Golgi/trans-Golgi network to the plasma membrane (Gasparini et al., 2001). An insulin resistant state would interfere with this action of insulin and reduce trafficking of $A \beta$ out of the cell.

A significant factor in $A \beta$ degradation is the metalloprotease insulin-degrading enzyme (IDE; Cook et al., 2003; Farris et al., 2003; Zhao L. et al., 2004). IDE is highly expressed in tissue throughout the body, including brain, liver, skeletal muscle and kidney (Authier et al., 1996). Importantly, IDE has been described to facilitate the breakdown of both insulin and $A \beta$ (Kurochkin and Goto, 1994; McDermott and Gibson, 1997; Qiu et al., 1998; Sudoh et al., 2002; Zhao L. et al., 2004). The IDE-dependent degradation of $\mathrm{A} \beta$ has been shown to occur through a PI3K-dependent mechanism (Zhao L. et al., 2004). Thus, an early insulin-resistant state (with higher levels of circulating insulin) may contribute to the accumulation of $\mathrm{A} \beta$ due to competition for IDE (Qiu et al., 1998; Roriz-Filho et al., 2009; Bosco et al., 2011). Research in AD mouse models has further solidified the role of insulin resistance in IDE-related amyloid pathology. Tg2576 mice with diet-induced insulin resistance had increased production of $A \beta$ (1-40 and 1-42) in the brain relative to $\operatorname{Tg} 2576$ mice without insulin resistance. Interestingly, these results were associated with an increased gamma-secretase activity and decreased IDE activity (Ho et al., 2004). Moreover, IDE knockout mice have been shown to have a reduced breakdown of cerebral $\mathrm{A} \beta$ and insulin (Pérez et al., 2000; Cook et al., 2003; Farris et al., 2003). These results suggest that insulin resistance may independently contribute to amyloid production and exacerbate an already amyloidogenic state, such as $\mathrm{AD}$.

Chronically elevated peripheral insulin may lead to lower levels of insulin within the CNS (Wallum et al., 1987; Schwartz et al., 1990; Banks et al., 2012). Initially cerebral levels of insulin may be increased (as with the periphery), yet insulin eventually decreases as BBB transport is reduced and amyloid accumulates, promoting central insulin resistance (Banks et al., 1997b). This process may negatively impact insulin's functions in the brain and the clearance of $\mathrm{A} \beta$. Patients with $\mathrm{AD}$ have been shown to have lower insulin in the CSF, elevated insulin in the blood, and a lower CSF:Plasma insulin ratio relative to healthy controls (Craft et al., 1998). Furthermore, increased peripheral insulin concentration may interrupt breakdown of $\mathrm{A} \beta$ after being transported out of the brain as well as by interfering with its exit from the brain. A potential mediator of these effects is LDL receptor-related protein (LRP-1). Tamaki et al. (2007) reported that insulin mediates the hepatic uptake of circulating $A \beta$ (1-40) from the blood by increasing LRP-1 
expression on hepatic cellular plasma membranes. This process is dose-dependent and reversed with administration of an LRP-1 inhibitor (Tamaki et al., 2007). LRP-1 has also been shown to contribute to $\mathrm{A} \beta(1-40)$ transport across the $\mathrm{BBB}$ to the peripheral circulation (Ito et al., 2006). These results suggest that insulin resistance may contribute to the accumulation of amyloid species due to impaired clearance from the brain to the periphery where it may be cleared by the liver. Both decreased removal of $A \beta$ from the CNS and reduced degradation of $A \beta$ once it reaches the periphery may contribute to the clogging of a peripheral $A \beta$ "sink." Thus, the pattern of high peripheral insulin levels and low brain insulin levels may increase risk for $\mathrm{AD}$ and ultimately help exacerbate disease pathology.

Additional mechanisms may relate insulin resistance to $\mathrm{AD}$ pathology. For example, the soluble form of $\mathrm{A} \beta$ is able to bind to the IR, and has been shown to disrupt insulin signaling and activation of three kinases in primary hippocampal neurons (Townsend et al., 2007). Specifically, A $\beta$ was shown to act through diminishing insulin-induced autophosphorylation (Townsend et al., 2007). Moreover, a study by Zhang et al. (2013) suggests that $A \beta$ promotes hepatic insulin resistance through JAK2 signaling. Taken together these results infer that over accumulation of $A \beta$ may promote impaired insulin signaling that could further propagate disease pathology. Synaptotoxic effects also link $A \beta$ and insulin. Synapse loss is an early event in $A D$ pathology, which may be promoted by soluble $A \beta$ oligomers (Selkoe, 2002; Scheff et al., 2006). Insulin has been shown to prevent binding of $A \beta$ to synapses, thus minimizing synaptic damage (De Felice et al., 2009). Insulin has also been shown to diminish formation of $\mathrm{A} \beta$ oligomers, which is likely protective against $A \beta$ oligomer-related damage (Lee et al., 2009). This research suggests that a pathologic hallmark of $\mathrm{AD}$ initiated by $\mathrm{A} \beta$ oligomers may be mitigated by insulin administration. Inflammation, dyslipidemia, and amyloidogenesis are each prominent features linking insulin resistance and $\mathrm{AD}$. Yet, one of the most important connections between the two pathologies is the inherent bioenergetic dysfunction that is common to each.

\section{Bioenergetic Dysfunction in Insulin Resistance and Alzheimer's Disease}

Another common feature of $\mathrm{AD}$ and insulin resistance is mitochondrial dysfunction, which is supported by several key findings (Lowell and Shulman, 2005; Kim et al., 2008; Szendroedi et al., 2011; Johri and Beal, 2012; Chaturvedi and Beal, 2013). First, enzymes involved in energy metabolism are differentially regulated in $\mathrm{AD}$. Lower activity of the pyruvate dehydrogenase $(\mathrm{PDH})$ and alpha-ketoglutarate dehydrogenase (AKGDH) complexes has been reported in AD (Park et al., 1999; Blass, 2000; Starkov et al., 2004). These enzymes are fundamental for cellular respiration, with $\mathrm{PDH}$ being particularly important for linking glycolytic metabolism to the Kreb's cycle. Like many bioenergetic enzymes, both may be affected by the accumulation of oxidative moieties leading to decreased enzyme efficiency and ultimate production of reactive oxygen species (ROS) and further oxidative stress (Wei and Lee, 2002).
Second, mitochondrial function in adults with $\mathrm{AD}$ may be affected by the accumulation of $A \beta$, which seems to be at least partly mediated by $A \beta$-binding-alcohol-dehydrogenase (ABAD; Yao et al., 2011; Chaturvedi and Beal, 2013). Specifically, A $\beta$ has been shown to inhibit activity of complexes II and IV of the electron transport chain (ETC) and lead to increased production of ROS (Swerdlow et al., 2010; Yao et al., 2011; Chaturvedi and Beal, 2013). Reduced activity of complex IV, also known as cytochrome c oxidase (COX), has been widely reported in platelets as well as within the brain, which supports the view of AD being a systemic disorder (Parker et al., 1990; Cardoso et al., 2004). A $\beta$ and APP have been implicated in the disruption of mitochondrial dynamics (fission/fusion), contributing to the mitochondrial dysfunction seen in AD (Wang et al., 2008, 2009; Chaturvedi and Beal, 2013).

Additionally, $A \beta$ has been shown to impair mitochondrial calcium homeostasis, which may lead to disruption of mitochondrial permeability transition pore and eventually cell death (Bezprozvanny and Mattson, 2008; Reddy, 2009). Insulin has also been described to impact intracellular calcium homeostasis. A recent study by the Thibault lab reported that acute insulin administration decreases calcium transients ultimately affecting the function of intracellular calcium channels (Maimaiti et al., 2017). Understanding this relationship is necessary, as higher levels of intracellular calcium may consequently disrupt physiologic glucose metabolism in the brain; potentially promoting further pathology (Pancani et al., 2011).

Epidemiological evidence has described parental history of $\mathrm{AD}$ as being an important predisposition to developing the disease (Fratiglioni et al., 1993). The risk may be more prominent for maternal than paternal history and lead to $\mathrm{AD}$-related brain changes, even in cognitively normal adults (Edland et al., 1996; Mosconi et al., 2007, 2009a). As mitochondrial DNA (mtDNA) is inherited from the mother, any maternal genetic predispositions for bioenergetic disturbances may be passed down leading to increased risk for disease (Taylor and Turnbull, 2005).

Even prior to the first articles concerning an Amyloid Cascade Hypothesis of AD (Hardy and Higgins, 1992), evidence described mitochondrial/bioenergetic disturbances in $\mathrm{AD}$ (Sims et al., 1987; Parker et al., 1990; Blass and Gibson, 1991). Blass (2000) described a Mitochondrial Spiral as contributing significantly to $\mathrm{AD}$ pathogenesis. Three main points were discussed: reduced brain (glucose) metabolism, oxidative stress and calcium dysregulation. Deficiencies in either of these domains may ultimately led to disruption in the others-contributing to the pathogenesis of AD (Blass, 2000). Swerdlow and Khan (2004) proposed a Mitochondrial Cascade Hypothesis of sporadic AD. This theory of $\mathrm{AD}$ pathogenesis identifies the mitochondria and mitochondrial dysfunction as a central mediator in the development of LOAD. The inheritance of genes important for bioenergetic processes combined with various environmental influences throughout life could lead to the pathological changes associated with $\mathrm{AD}$. One such environmental influence is insulin resistance. The impaired energy metabolism seen in insulin resistance may catalyze the bioenergetic deficits that contribute to the mitochondrial dysfunction seen in $\mathrm{AD}$ (Correia et al., 2012; 
Montgomery and Turner, 2015). Disrupted insulin signaling leads to impaired energy metabolism, likely affecting the bioenergetic machinery working to maintain an adequate supply of energy for bodily function. There is still debate whether insulin resistance leads to mitochondrial dysfunction, if mitochondrial dysfunction contributes to insulin resistance, or if they mutually impact each other (Montgomery and Turner, 2015). Regardless of causality, mitochondrial dysfunction is fundamental feature of insulin resistance. Thus, insulin resistance may either promote or intensify the bioenergetic dysfunction already apparent in $\mathrm{AD}$.

\section{CEREBRAL METABOLISM AND THE BIOENERGETIC SHIFT IN ALZHEIMER'S DISEASE}

Given the systemic metabolic dysfunction seen in $\mathrm{AD}$ potentially promoted by insulin resistance, it is important to understand the various metabolic fuels that may be used by the brain and how our current knowledge of brain metabolism is limited by the study of mainly one of these fuels. In this section, we will also discuss a potential bioenergetic shift in brain metabolism in AD and how this may be visualized with neuroimaging techniques prior to significant disease pathology.

\section{Metabolic Fuels}

Several sources of energy may be utilized in the production of adenosine triphosphate (ATP) that is required for many physiologic processes (Wallace et al., 2010). It is well established that glucose is the primary source of brain metabolic energy for healthy individuals. The interaction between neurons and glia, especially astrocytes, is fundamental for brain energy metabolism (Pellerin et al., 2007; Bélanger et al., 2011); and must be appreciated when interpreting results of cerebral metabolic studies. Glucose may be metabolized into pyruvate and lactate, via erobic and anerobic glycolysis, both of which have received attention concerning their roles in brain metabolism (Gonzalez et al., 2005; Boumezbeur et al., 2010; Barros, 2013). Furthermore, accumulating evidence describes the importance of erobic glycolysis in brain function (Vaishnavi et al., 2010; Vlassenko et al., 2010).

When glucose is in excess it is stored as glycogen, which is largely stored in the liver for systemic use and in the skeletal and cardiac muscle for local utilization (Shulman et al., 1990; Roden et al., 1996). However, glycogen has also been found within brain astrocytes (Brown and Ransom, 2007). There is debate to how long these stores may provide energy for the brain. Yet, astrocytic stores likely make glycogen an important source of cerebral fuel in times of need.

In addition to glucose and its derivatives, other sources may be used as metabolic fuels. Beta-oxidation of fatty acids may be a significant source of fuel for systemic energy metabolism, especially at times when glucose and glycogen reserves are depleted or within states of diminished glucose metabolism (Cahill, 2006). Even though fatty acids may cross the BBB, they are not the preferred alternate substrate to glucose for brain metabolism. Schonfeld and Reiser suggest that fatty acids may be less efficient with a slower rate of oxidation than glucose and ketone bodies, while being associated with higher rates of oxidative stress (Schönfeld and Reiser, 2013).

Ketone bodies (acetoacetate (AcAc), beta-hydroxybutyrate (BHB) and acetone) or $\mathrm{KB}$ are mainly synthesized in the liver as a result of beta-oxidation of fatty acids and are the primary alternative fuel to glucose in brain metabolism (Garber et al., 1974). They are released in marginal amounts in healthy individuals, and in times of fast or on a high fat ketogenic diet levels are increased compensating for decreased glucose metabolism (Cahill, 2006). Ketone bodies are more efficient than glucose relative to the amount of oxygen needed to carry out oxidative metabolism (Cahill, 2006). The lower amount of oxygen required for $\mathrm{KB}$ metabolism not only conserves the use of a vital resource (especially in hypoxic states), but it leads to decreased generation of ROS that may promote cellular damage and eventual cell death. Furthermore, increased KB metabolism may lead to an improved glucose metabolism, which may add to the efficacy of a therapy aimed at ketosis (Roy et al., 2012). In states where circulating $\mathrm{KB}$ are elevated, transporters regulating their flux into the $\mathrm{BBB}$ are upregulated. These monocarboxylate transporters (MCTs) are known to transport various substrates depending on their class, including: $\mathrm{KB}$, lactate, pyruvate and thyroid hormone (Halestrap and Wilson, 2012).

In the brain, MCTs are found in the cell membranes of neurons and glia in addition to the BBB. Even though $\mathrm{KB}$ only marginally contribute to brain metabolism under basal conditions in a healthy individual, they may constitute over $60 \%$ of brain energy metabolism during the fasted state, and help mitigate decreased glucose metabolism (Morris, 2005). There are three main determinants of $\mathrm{KB}$ use by the brain: concentration of $\mathrm{KB}$ in the blood, transport across the $\mathrm{BBB}$ via MCTs, and cerebral activity of enzymes used in $\mathrm{KB}$ metabolism (Morris, 2005). KBs become a significant source of metabolic fuel as their plasma concentration increases. After transport across the BBB, research suggests that the rate-limiting factor in the utilization of $\mathrm{KB}$ is activity of catalytic enzymes that may regionally vary throughout the brain (Morris, 2005). However, other research describes the rate-limiting step after acute $\mathrm{KB}$ administration as transport across the BBB (Blomqvist et al., 2002). MCTs on the $\mathrm{BBB}$ are upregulated in states of chronic ketosis (Halestrap and Wilson, 2012). With an acute administration of KB, MCT density on the $\mathrm{BBB}$ may be the rate-limiting step for the ability of $\mathrm{KB}$ to be used in brain metabolism, while in a chronic state of ketosis the environment is adapted to a state of decreased glucose metabolism and may be dependent on the ketolytic metabolic machinery.

\section{Brain Hypermetabolism in Alzheimer's Disease and Related Disorders}

One of the most prominent features of the underlying mitochondrial and metabolic abnormalities in $\mathrm{AD}$ may be brain glucose hypometabolism. Disrupted cerebral glucose metabolism is visible using FDG PET and one of the earliest pathologic events in AD (Mosconi, 2005; Mosconi et al., 2008; Sperling et al., 2011). The hypometabolic pattern seen in $\mathrm{AD}$ is fairly characteristic. Metabolic declines are first found in the parietal-temporal 
area, posterior cingulate cortices and medial temporal lobes. Hypometabolism eventually progresses to the frontal lobes, subcortical areas and the cerebellum (Mosconi et al., 2009b). This may occur more than a decade prior to clinical onset of $\mathrm{AD}$ and is most evident in individuals that carry an APOE4 allele or with a positive family history (especially maternal history) of dementia (Mosconi et al., 2009b; Cunnane et al., 2011; Sperling et al., 2011). However, in recent years mounting evidence has described a state of reactive or compensatory glucose hypermetabolism in $\mathrm{AD}$ as well as Parkinson's, Huntington's and other neurologic diseases (Gilman et al., 1990; Haier et al., 2003; Borghammer et al., 2012; Cistaro et al., 2012; Lee et al., 2012; Ashraf et al., 2015).

Ashraf et al. (2015) reported cortical glucose hypermetabolism in individuals with amnestic MCI. Glucose hypermetabolism was found in amyloid (11C-PiB PET) negative $(n=4)$ and amyloid positive $(n=1)$ participants. Opposing results were seen in participants with the highest amyloid load $(n=5)$, which were found to have cortical glucose hypometabolism. Interestingly, amyloid negative participants with glucose hypermetabolism did not convert to $\mathrm{AD}$ within an 18-month follow-up, while amyloid positive participants $(n=4)$ did convert to AD within the same time period (Ashraf et al., 2015). Results from this study suggest that cerebral glucose hypermetabolism may precede glucose hypometabolism in the earliest stages of $\mathrm{AD}$ pathology.

Findings of compensatory hypermetabolism in a clinical population with $\mathrm{MCI} / \mathrm{AD}$ have been supported by evidence describing a similar cerebral metabolic profile in $\mathrm{AD}$ mouse models. In the APP/PS1 mouse model of AD, Poisnel et al. (2012) found cortical and hippocampal glucose hypermetabolism in APP/PS1 mice relative to controls at 12 months. Moreover, the group used autoradiography to show that the increased glucose uptake was generally limited to areas near amyloid plaque accumulation (Poisnel et al., 2012). Similar results have been found in the 5xFAD (Rojas et al., 2013) and Tg2576 mouse models of AD (Luo et al., 2012).

Cerebral glucose hypermetabolism has also been described in several other neurologic disorders, commonly preceding a state of impaired glucose metabolism in a disease-specific manner. In Huntington's disease (HD), relative cerebral glucose hypermetabolism has been described in several brain areas including the thalamus, while hypometabolism was seen in the striatum (Lee et al., 2012). In Parkinson's disease (PD), hypermetabolism has been found in the globus pallidus externus and other subcortical areas. This contrasts the near-global cortical hypometabolism seen in PD (Borghammer et al., 2012). Patients with bulbar and spinal-onset Amyotrophic Lateral Sclerosis (ALS) had higher glucose metabolism on FDG PET than controls in several regions of interest (ROIs), including the amygdala, midbrain, pons, and cerebellum. While lower glucose metabolism was found in frontal/parietal lobes in those with bulbar-onset alS relative to spinal-onset patients and controls (Cistaro et al., 2012). In Down Syndrome, inferior temporal lobe and entorhinal cortex hypermetabolism has been reported prior to the onset of dementia, which may be a compensatory response to early pathologic changes (Haier et al., 2003, 2008).
Similar evidence has been found in the study of Friedreich's ataxia, where glucose hypermetabolism was reported in those with early disease. An apparent glucose hypometabolic state was associated with further progression of the clinical condition. This difference between hypermetabolic to hypometabolic state was noted by authors to be regionally specific (Gilman et al., 1990). In theory, similar metabolic changes could occur in a diseasespecific pattern in any disorder of the CNS with significant neurodegenerative pathology.

Intriguingly, cerebral energy metabolism may be impacted by systemic metabolic disease without clinically defined neuropathology. In Willette et al. (2015a) examined the relationship of systemic insulin resistance (HOMA-IR) and cerebral glucose metabolism. They found a higher degree of insulin resistance was related to lower glucose metabolism in AD ROIs. Conversely, in participants with MCI that eventually progressed to $\mathrm{AD}$, higher HOMA-IR was associated with glucose hypermetabolism in the medial temporal lobes and hippocampus (Willette et al., 2015a,b). These results suggest that there may be a differential cerebral metabolic response throughout the clinical spectrum of $\mathrm{AD}$ and highlight the importance of studying the relation of brain metabolism to systemic metabolic risk factors. Moreover, our lab has previously reported that older adults with insulin resistance showed AD-like patterns of reduced brain glucose metabolism, as quantified with FDG PET imaging. Glucose hypometabolism was most apparent in frontal, parietotemporal, and cingulate cortices (Baker et al., 2011). This suggests that insulin resistance may promote AD-related changes in brain in those at-risk for the disorder.

Although underlying synaptic dysfunction and neuronal degeneration likely promotes decreased glucose utilization in the brain (cerebral glucose hypometabolism on FDG PET imaging) there is still debate as to whether an inherent glucose hypometabolism causes the early pathologic changes seen in $\mathrm{AD}$ and related disorders. A review by Cunnane et al. (2011) explores this topic by offering several mechanisms by which glucose hypometabolism may contribute to AD-related pathology. Potential mechanisms described include tau hyperphosphorylation resulting from lower glucose availability, decreased glycolytic enzyme activity-with a potential impact on cholinergic neurotransmission, and brain microvascular changes that may disrupt glucose influx into the brain (Cunnane et al., 2011). Yet, another potential mediator of the AD-related brain glucose changes may be a bioenergetic shift in metabolism from glucose-based to KB-based.

\section{Brain Bioenergetic Shifts and Alzheimer's Disease Pathogenesis}

The notion of a bioenergetic shift in energy metabolism in AD has been described in the literature spurred by observations concerning the metabolic deficits commonly seen in the disorder-especially glucose hypometabolism, mitochondrial dysfunction and oxidative stress (Kadish et al., 2009; Yao et al., 2011). Important work has come from Roberta Brinton and colleagues, who have described brain changes resulting from a potential bioenergetic shift, with special interest in 
how this shift is impacted by estrogen (Brinton, 2008a,b; Yao et al., 2009, 2010, 2011, 2012; Yao and Brinton, 2012; Ding et al., 2013a,b). Evidence using a female triple transgenic AD mouse model (3xTg-AD) and non-transgenic mice describes an upregulation of succinyl-CoA:3-ketoacid coenzyme A transferase (SCOT) and hydroxyacyl-coenzyme A dehydrogenase (HADH) during reproductive senescence (Yao et al., 2010). SCOT is an important enzyme for $\mathrm{KB}$ energy metabolism, while $\mathrm{HADH}$ is an enzyme with a role in the beta-oxidation of fatty acids (Fukao et al., 1997; Houten and Wanders, 2010). Notably, this upregulation of SCOT and HADH occurred concurrent with the decreased activity of $\mathrm{PDH}$, an important enzyme in glucose energy metabolism (Yao et al., 2010). When coupled with an apparent inefficiency of glucose metabolism in $\mathrm{AD}$, an upregulation of genes involved in $\mathrm{KB}$ (and fatty acid) metabolism strongly supports a bioenergetic shift phenomenon.

In a state where glucose metabolism is disrupted, it would be beneficial to increase the fraction of metabolism that is contributed by an alternate source of fuel. Genes involved in $\mathrm{KB}$ and fatty acid metabolism would be upregulated, while genes driving glycolytic metabolism may be downregulated. However, even with a change in metabolic machinery favoring $\mathrm{KB}$ and fatty acid metabolism, if the newly preferred metabolic fuel is not supplied through diet then it must come another source. When exogenous glucose supply is low in a healthy adult, glucose is derived from the breakdown of stored glycogen and through gluconeogenesis (Cahill, 2006). If glycogen stores are depleted and the amount of gluconeogenesis is not sufficient to meet energy demands, then the use of fats, $\mathrm{KB}$, and even amino acids (in later stages) are utilized as fuel by the body (Cahill, 2006). If an individual is progressing through a systemic bioenergetic shift in which the preferred brain fuel substrate are $\mathrm{KB}$ and there is an inadequate supply of this fuel through exogenous intake, then the fuel must come from an endogenous source. Adipose tissue reserves are generally sizeable enough to supply fuel through beta-oxidation of fatty acids, leading to the production of $\mathrm{KB}$ that are largely produced by the liver (Garber et al., 1974). Ketone bodies can then be transported to the brain across the BBB for use in the production of ATP (Halestrap and Wilson, 2012). As circulating levels of KB become elevated brain usage increases; with capacity for utilization limited by expression of ketolytic enzymes (Morris, 2005). Over time, however, the capacity to compensate with peripheral $\mathrm{KB}$ production may diminish without proper exogenous supply through diet or supplementation (Yao et al., 2011). This could lead to a state where the brain becomes dependent on itself as a source of fatty acids and $\mathrm{KB}$.

The myelin insulating neuronal axons in the brain is largely made of various lipids, cholesterol and proteins (Quarles et al., 2006). Thus, it may be a ready source of the fatty acid fuel that may be metabolized into $\mathrm{KB}$ for use by the brain. Phospholipase-A2 (PLA2) is an enzyme that catalyzes the cleavage of fatty acids from phospholipids (mainly in cellular membranes) as well as the release of arachidonic acid (AA) and eicosanoid synthesis (Sun et al., 2004; Adibhatla and Hatcher, 2008). When PLA2 is activated in the brain, it may lead to the breakdown of myelin (Adibhatla and Hatcher, 2008), releasing fatty acids for potential use as fuel with ultimate conversion to $\mathrm{KB}$ with interaction between astrocytes and neurons. An increased production of ROS, such as hydrogen peroxide, seen in mitochondrial dysfunction also leads to an activation of PLA2 provoking further myelin breakdown (Adibhatla and Hatcher, 2008; Sun et al., 2010; Yao et al., 2011). As the myelin is degraded, white matter changes may become apparent through various neuroimaging modalities and over time may contribute to gross volumetric loss and cognitive changes. White matter abnormalities are a common pathology seen as early as preclinical AD (Burns et al., 2005; Medina et al., 2006). Furthermore, PLA2 has been associated with the pathological response associated with $A \beta$ (Zhu et al., 2006) and has been shown to be increased in the AD brain (Sanchez-Mejia et al., 2008). Work by Sanchez-Mejia et al. (2008) showed that a reduction in PLA2 activation diminished the PLA2-associated neurotoxicity and learning/memory deficits. Thus, the underlying AD-related $\mathrm{A} \beta$ accumulation, mitochondrial dysfunction, and bioenergetic shift may each contribute to the activation of PLA2 and ultimately lead to characteristic pathology of the disorder. Yet, it remains to be determined to what extent each of the mediators of PLA2 activation is the primary contributor.

Additional evidence of a bioenergetic shift in $\mathrm{AD}$ is the weight changes that are seen in the disorder (White et al., 1998). Individuals prior to $\mathrm{AD}$ diagnosis on average tend to weigh more than the general population. Starting with preclinical disease and progression to MCI and Alzheimer's dementia there seems to be a significant weight loss with each stage of decline (White et al., 1998; Johnson et al., 2006). This may be due to a combination of factors, such as decreased appetite, co-morbid depression, and impairments in various cognitive functions (Gillette-Guyonnet et al., 2000). Yet, these weight changes may also relate to the bioenergetic shift in energy metabolism.

Given the current evidence and need to understand $\mathrm{AD}$ pathologic processes, we support an updated model for cerebral metabolic changes in $\mathrm{AD}$. The ultimate endpoint of brain energy utilization in $\mathrm{AD}$ and many other disorders is hypometabolism, however, a hypermetabolic glucose compensatory response may result from pathology early in disease progression (pre-clinical stage). With increased demand for energy and/or decreasing efficiency of glucose metabolism, alternate fuels (i.e., ketone bodies) may also supplement glucose metabolism. With worsening pathology and significant cell death, global hypometabolism develops. It is likely that these CNS metabolic changes may be provoked by systemic disease. Figure 1 displays a representation of the metabolic transitions we hypothesize are seen throughout the continuum of sporadic AD.

If a metabolic bioenergetic shift is indeed a feature of $\mathrm{AD}$, several key questions remain to be answered. What causes this shift? Is it an inherent defect in mitochondrial bioenergetics or a result of amyloid, tau, and other AD-related pathology? How do diseases of systemic metabolic dysfunction (insulin 


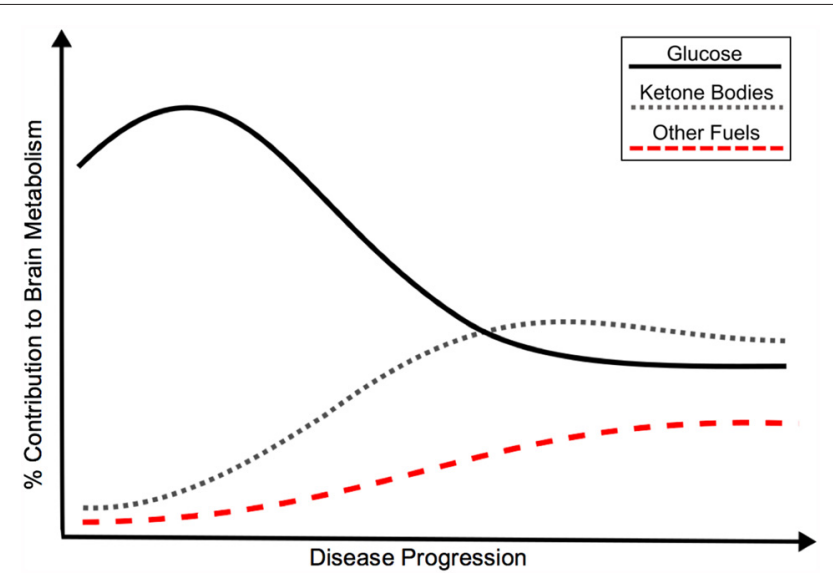

FIGURE 1 | Hypothetical model of the bioenergetic shift in energy metabolism in Alzheimer's disease (AD), as represented by relative contribution of glucose, ketone bodies and other fuels to brain metabolism. Although classically associated with glucose hypometabolism, recent evidence points to an initial glucose hypermetabolic state with potential shift towards use of alternate fuels. Insulin resistance may promote the development of AD through a variety of mechanisms, including a shift in energy metabolism. The bioenergetic shift may also be an independent feature of AD pathology. Black: Glucose metabolism; Gray: Ketone body metabolism; Red: Other fuel metabolism.

resistance, hyperlipidemia, etc.) impact the development of a bioenergetic shift and how does this relate to the susceptibility to develop $\mathrm{AD}$ ? Further research into the role of metabolic dysfunction and mitochondrial bioenergetics in $\mathrm{AD}$ may answer these questions and ultimately fortify our understanding of $\mathrm{AD}$ pathogenesis.

\section{Neuroimaging Biomarkers of Bioenergetic Shift in Alzheimer's Disease}

Our ability to study the bioenergetic changes in $\mathrm{AD}$ is enhanced by newly developed imaging techniques, which may ultimately lead to the identification of a biomarker at the earliest signs of metabolic disturbance in $\mathrm{AD}$ and a way to quantify changes secondary to therapeutic intervention.

Although functional imaging of glucose metabolism via FDG PET is commonly used in research and clinical settings, solely visualizing brain glucose metabolism does not provide a comprehensive understanding of the brain's differential use of fuels. In order to appreciate the bioenergetic shift that potentially contributes to the pathogenesis of $\mathrm{AD}$, it is important to study the use of $\mathrm{KB}$, as they are the primary alternate fuel for brain metabolism. Several neuroimaging methods may be utilized for the study of brain KB metabolism, including PET with tracers developed for individual $\mathrm{KB}$ and magnetic resonance spectroscopy (MRS; Blomqvist et al., 1995, 2002; Pan et al., 2000; Tremblay et al., 2007, 2008).

Literature regarding the utilization of PET imaging for cerebral alternate energy metabolism is relatively scarce, largely originating from two main laboratories. Work from Blomqvist et al. $(1995,2002)$ described the use of carbon-11 labeled BHB PET imaging. $\mathrm{BHB}$ is one of the $\mathrm{KB}$ utilized by the brain and can be readily measured peripherally in the blood (Garber et al., 1974). Studies using this tracer described a BBB transportdependent uptake of $\mathrm{BHB}$ after acute infusion of the $\mathrm{KB}$ (Blomqvist et al., 1995, 2002). Findings suggested no significant difference in uptake or utilization of BHB in metabolically healthy subjects and those who had insulin dependent (type 1) diabetes (Blomqvist et al., 2002). An earlier study by the group using the same tracer described $\mathrm{BHB}$ utilization increasing linearly with peripheral concentration and showed higher BHB utilization in gray over white matter (Blomqvist et al., 1995). These results were important in establishing a PET technique that may be utilized to visualize differential brain metabolism. Moreover, they provide valuable evidence to how KB utilization changes with peripheral concentration.

More recently, Cunnane and colleagues have developed a carbon-11 labeled radiotracer of AcAc, the other major $\mathrm{KB}$ utilized by the brain, for use in PET imaging of brain $\mathrm{KB}$ metabolism (Tremblay et al., 2007). Their work describes use of the tracer in rat models of aging and on ketogenic interventions and clinical studies. Results suggest an increased KB uptake in young and aged rats during a ketogenic intervention (Bentourkia et al., 2009; Roy et al., 2012). Importantly elevated cerebral $11 \mathrm{C}$-AcAc uptake corresponds to amount of peripheral $\mathrm{KB}$ levels (Bentourkia et al., 2009; Roy et al., 2012). Although the use of an AcAc tracer is exciting and informative, the Cunnane group has implemented a novel dual-tracer PET approach with $11 \mathrm{C}$-AcAc and 18F-FDG at the same imaging session. Several articles in the human population and within rodent models have utilized this dual-tracer technique (Roy et al., 2012; Nugent et al., 2014; Castellano et al., 2015). In a comparison of healthy young (mean age $=26$ years) and older adults (mean age $=74$ years), both glucose and AcAc metabolism was decreased in older adults relative to the younger cohort (Nugent et al., 2014). A 2015 study has explored cerebral glucose and AcAc metabolism in AD (Castellano et al., 2015). They described a reduction in cerebral glucose metabolism in older adults with mild $\mathrm{AD}$ relative to age-matched controls. Interestingly, AcAc did not differ between the groups (Castellano et al., 2015), which may provide a therapeutic outlet for those with $\mathrm{AD}$ and related disorders. This dual-tracer technique has the potential to greatly expand our understanding of brain metabolism in healthy vs. pathological conditions, how it is affected in "normal aging" as well as in AD. There is much to be gained from the study of brain KB metabolism, especially when coupled with glucose metabolism. The ability to visualize the bioenergetic shift in energy metabolism may provide further insight into the development of $\mathrm{AD}$ and ultimately act as an early biomarker for $\mathrm{AD}$ and the ability to determine individuals that may benefit from therapies aimed at providing $\mathrm{KB}$ as an alternative source of fuel for therapeutic treatment.

\section{CONCLUSION}

In this review, we have discussed the contribution of insulin resistance to the pathogenesis of $\mathrm{AD}$, in particular how insulin resistance may induce a bioenergetic shift in peripheral and CNS energy metabolism, while closing with a review of neuroimaging 
biomarkers that may be used to identify and better understand the bioenergetic changes seen in $\mathrm{AD}$ and potentially response to preventative and therapeutic interventions.

We remain at a time where we have made significant progress in understanding $\mathrm{AD}$ without any disease-modifying therapeutics or proven prevention strategies. Yet, we now have the opportunity to explore new areas of research that may expand our knowledgebase and provide a more comprehensive view of $\mathrm{AD}$ pathogenesis. One of the most vital areas of need is the study of brain metabolism. Until now we have largely discussed glucose as being the sole player in brain metabolism. In fact, when brain energy is discussed, it is implied that we are referring to glucose metabolism (i.e., cerebral [glucose] metabolism). We take for granted our knowledge that glucose is the primary fuel-that higher uptake is better and that in almost every neurologic and psychiatric condition, glucose metabolism is diminished (Mosconi et al., 2009b; Wallace et al., 2010; Bélanger et al., 2011; Bohnen et al., 2012). Studies describing a state of compensatory or reactive glucose hypermetabolism that precedes significant clinical decline are overshadowed by reports of the hypometabolic state commonly assumed in most neurologic disorders (Bohnen et al., 2012; Borghammer et al., 2012; Cistaro et al., 2012; Lee et al., 2012; Ashraf et al., 2015). Although the cause of this hypermetabolism is not definitively known, it is most likely a compensatory response to injury and initial pathologic processes (Ashraf et al., 2015). If this was an isolated phenomenon, it would be easy to dismiss. However, it has been reported in conditions from Alzheimer's, Parkinson's, Huntington's and ALS, to Down Syndrome, Friedrich's Ataxia and familial CreutzfeldtJakob disease in disease-specific patterns (Gilman et al., 1990; Haier et al., 2003; Nagasaka et al., 2011; Borghammer et al., 2012; Cistaro et al., 2012; Lee et al., 2012; Ashraf et al., 2015).

The view of a glucose hypermetabolic state as an early disease event and response to initial pathology is likely a temporary solution to injury with an ultimate decline to decreased glucose utilization. If further evidence supports the occurrence of an initial rise and ultimate decline of cerebral glucose metabolism, then it possible to visualize this shift early (prior to clinical symptomology) and work to prevent the underlying pathology. This primary glucose hypermetabolic shift is likely also supplemented with a increase in utilization of other fuels. With progression of the disease, a potential bioenergetic

\section{REFERENCES}

Abbatecola, A. M., Paolisso, G., Lamponi, M., Bandinelli, S., Lauretani, F., Launer, L., et al. (2004). Insulin resistance and executive dysfunction in older persons. J. Am. Geriatr. Soc. 52, 1713-1718. doi: 10.1111/j.1532-5415.2004. 52466.x

Abbott, M. A., Wells, D. G., and Fallon, J. R. (1999). The insulin receptor tyrosine kinase substrate p58/53 and the insulin receptor are components of CNS synapses. J. Neurosci. 19, 7300-7308.

Adibhatla, R. M., and Hatcher, J. F. (2008). Phospholipase $A_{2}$, reactive oxygen species, and lipid peroxidation in CNS pathologies. BMB Rep. 41, 560-567. doi: 10.5483/bmbrep.2008.41.8.560 shift may occur with decreasing reliance on glucose and increased use of alternate energy sources, see Figure $\mathbf{1}$.

Despite the brain's metabolic flexibility, most alternate fuels have been inadequately studied. These are sources of energy that our bodies use on a daily basis. Ketone bodies are an optimal first alternate fuel to study as they have been commonly reported to be the chief alternate source of cerebral energy (Cahill, 2006). Yet, acetate, lactate, pyruvate, amino acids or even glycogen remain largely unstudied (Gonzalez et al., 2005; Boumezbeur et al., 2010; Wallace et al., 2010; Barros, 2013; Cunnane et al., 2016). It is crucial to understand the brain's use of different fuels and how this may change throughout progression of disease. This enables us to appreciate pathophysiology and the body's response to increasing pathology. Moreover, we may be able to characterize "brain metabolic fingerprints" that may be used to offer patients and research participants more personalized therapeutic options if they were to develop a condition impacting brain metabolism. Strategies for prevention and therapeutic approaches may be developed to improve metabolism and clinical function. Importantly, due to the metabolic changes commonly seen in brain disease, any findings from the study of one disorder may have broad application to other neurologic, psychiatric, as well as systemic metabolic conditions.

Studying the brain in any context is truly a new frontier, and we have only recently had the opportunity and tools to study its majesty. By investigating areas such as differential brain energy metabolism, we have the opportunity to greatly advance our understanding of how our brains function in health and disease. Many mysteries and questions remain-and if answered may lead to the successful treatment and prevention of some of the most terrifying diseases of our time.

\section{AUTHOR CONTRIBUTIONS}

BJN and SC drafted, revised and approved final version of the manuscript.

\section{FUNDING}

This work was supported by National Institutes of Health grants R37-AG10880 (SC), R01-AG027415 (SC) and the Roena B. Kulynych Center for Cognition and Memory Research.

Agrawal, R., Tyagi, E., Shukla, R., and Nath, C. (2011). Insulin receptor signaling in rat hippocampus: a study in STZ (ICV) induced memory deficit model. Eur. Neuropsychopharmacol. 21, 261-273. doi: 10.1016/j.euroneuro.2010. 11.009

Akash, M. S., Rehman, K., and Chen, S. (2013). Role of inflammatory mechanisms in pathogenesis of type 2 diabetes mellitus. J. Cell. Biochem. 114, 525-531. doi: $10.1002 /$ jcb. 24402

Akiyama, H., Barger, S., Barnum, S., Bradt, B., Bauer, J., Cole, G. M., et al. (2000). Inflammation and Alzheimer's disease. Neurobiol. Aging 21, 383-421. doi: 10.1016/S0197-4580(00)00124-X

Alzheimer's Association. (2015). 2015 Alzheimer's disease facts and figures. Alzheimers Dement. 11, 332-384. doi: 10.1016/j.jalz.2015.02.003 
Amador-Ortiz, C., Lin, W. L., Ahmed, Z., Personett, D., Davies, P., Duara, R., et al. (2007). TDP-43 immunoreactivity in hippocampal sclerosis and Alzheimer's disease. Ann. Neurol. 61, 435-445. doi: 10.1002/ana.21154

Amor, S., Puentes, F., Baker, D., and Van Der Valk, P. (2010). Inflammation in neurodegenerative diseases. Immunology 129, 154-169. doi: 10.1111/j.13652567.2009.03225.x

Apelt, J., Mehlhorn, G., and Schliebs, R. (1999). Insulin-sensitive GLUT4 glucose transporters are colocalized with GLUT3-expressing cells and demonstrate a chemically distinct neuron-specific localization in rat brain. J. Neurosci. Res. 57, 693-705. doi: 10.1002/(sici)1097-4547(19990901)57:5<693::aid-jnr11>3.0. co; 2 - $\mathrm{x}$

Armstrong, R. A. (2011). The Pathogenesis of Alzheimer's disease: a reevaluation of the "amyloid cascade hypothesis". Int. J. Alzheimers Dis. 2011:630865. doi: $10.4061 / 2011 / 630865$

Ashraf, A., Fan, Z., Brooks, D. J., and Edison, P. (2015). Cortical hypermetabolism in MCI subjects: a compensatory mechanism? Eur. J. Nucl. Med. Mol. Imaging 42, 447-458. doi: 10.1007/s00259-014-2919-z

Attwell, D., and Laughlin, S. B. (2001). An energy budget for signaling in the grey matter of the brain. J. Cereb. Blood Flow Metab. 21, 1133-1145. doi: 10.1097/00004647-200110000-00001

Authier, F., Posner, B. I., and Bergeron, J. J. (1996). Insulin-degrading enzyme. Clin. Invest. Med. 19, 149-160.

Baker, L. D., Cross, D. J., Minoshima, S., Belongia, D., Watson, G. S., and Craft, S. (2011). Insulin resistance and Alzheimer-like reductions in regional cerebral glucose metabolism for cognitively normal adults with prediabetes or early type 2 diabetes. Arch. Neurol. 68, 51-57. doi: 10.1001/archneurol.2010.225

Banks, W. A., Jaspan, J. B., Huang, W., and Kastin, A. J. (1997a). Transport of insulin across the blood-brain barrier: saturability at euglycemic doses of insulin. Peptides 18, 1423-1429. doi: 10.1016/s0196-9781(97) 00231-3

Banks, W. A., Jaspan, J. B., and Kastin, A. J. (1997b). Selective, physiological transport of insulin across the blood-brain barrier: novel demonstration by species-specific radioimmunoassays. Peptides 18, 1257-1262. doi: 10.1016/s0196-9781(97)00198-8

Banks, W. A., Owen, J. B., and Erickson, M. A. (2012). Insulin in the brain: There and back again. Pharmacol. Ther. 136, 82-93. doi: 10.1016/j.pharmthera.2012. 07.006

Barros, L. F. (2013). Metabolic signaling by lactate in the brain. Trends Neurosci. 36, 396-404. doi: 10.1016/j.tins.2013.04.002

Baskin, D. G., Figlewicz, D. P., Woods, S. C., Porte, D. Jr., and Dorsa, D. M. (1987). Insulin in the brain. Annu. Rev. Physiol. 49, 335-347. doi: 10.1146/annurev.ph. 49.030187.002003

Baura, G. D., Foster, D. M., Porte, D. Jr., Kahn, S. E., Bergman, R. N., Cobelli, C., et al. (1993). Saturable transport of insulin from plasma into the central nervous system of dogs in vivo. A mechanism for regulated insulin delivery to the brain. J. Clin. Invest. 92, 1824-1830. doi: 10.1172/jci116773

Bélanger, M., Allaman, I., and Magistretti, P. J. (2011). Brain energy metabolism: focus on astrocyte-neuron metabolic cooperation. Cell Metab. 14, 724-738. doi: 10.1016/j.cmet.2011.08.016

Benedict, C., Hallschmid, M., Hatke, A., Schultes, B., Fehm, H. L., Born, J., et al. (2004). Intranasal insulin improves memory in humans. Psychoneuroendocrinology 29, 1326-1334. doi: 10.1016/j.psyneuen.2004. 04.003

Benedict, C., Kern, W., Schultes, B., Born, J., and Hallschmid, M. (2008). Differential sensitivity of men and women to anorexigenic and memoryimproving effects of intranasal insulin. J. Clin. Endocrinol. Metab. 93, 1339-1344. doi: 10.1210/jc.2007-2606

Bentourkia, M., Tremblay, S., Pifferi, F., Rousseau, J., Lecomte, R., and Cunnane, S. (2009). PET study of $11 \mathrm{C}$-acetoacetate kinetics in rat brain during dietary treatments affecting ketosis. Am. J. Physiol. Endocrinol. Metab. 296, E796-E801. doi: 10.1152/ajpendo. 90644.2008

Berti, V., Murray, J., Davies, M., Spector, N., Tsui, W. H., Li, Y., et al. (2015). Nutrient patterns and brain biomarkers of Alzheimer's disease in cognitively normal individuals. J. Nutr. Health Aging 19, 413-423. doi: 10.1007/s12603014-0534-0

Bezprozvanny, I., and Mattson, M. P. (2008). Neuronal calcium mishandling and the pathogenesis of Alzheimer's disease. Trends Neurosci. 31, 454-463. doi: 10.1016/j.tins.2008.06.005
Biessels, G. J., Strachan, M. W., Visseren, F. L., Kappelle, L. J., and Whitmer, R. A. (2014). Dementia and cognitive decline in type 2 diabetes and prediabetic stages: towards targeted interventions. Lancet Diabetes Endocrinol. 2, 246-255. doi: $10.1016 / \mathrm{s} 2213-8587(13) 70088-3$

Bingham, E. M., Hopkins, D., Smith, D., Pernet, A., Hallett, W., Reed, L., et al. (2002). The role of insulin in human brain glucose metabolism: an 18fluorodeoxyglucose positron emission tomography study. Diabetes 51, 3384-3390. doi: $10.2337 /$ diabetes.51.12.3384

Blasko, I., Stampfer-Kountchev, M., Robatscher, P., Veerhuis, R., Eikelenboom, P., and Grubeck-Loebenstein, B. (2004). How chronic inflammation can affect the brain and support the development of Alzheimer's disease in old age: the role of microglia and astrocytes. Aging Cell 3, 169-176. doi: 10.1111/j.1474-9728.2004. 00101.x

Blass, J. P. (2000). The mitochondrial spiral. An adequate cause of dementia in the Alzheimer's syndrome. Ann. N Y Acad. Sci. 924, 170-183. doi: 10.1111/j. 1749-6632.2000.tb05576.x

Blass, J. P., and Gibson, G. E. (1991). The role of oxidative abnormalities in the pathophysiology of Alzheimer's disease. Rev. Neurol. (Paris) 147, 513-525.

Blázquez, E., Velázquez, E., Hurtado-Carneiro, V., and Ruiz-Albusac, J. M. (2014). Insulin in the brain: its pathophysiological implications for states related with central insulin resistance, type 2 diabetes and Alzheimer's disease. Front. Endocrinol. (Lausanne) 5:161. doi: 10.3389/fendo.2014. 00161

Blomqvist, G., Alvarsson, M., Grill, V., Von Heijne, G., Ingvar, M., Thorell, J. O., et al. (2002). Effect of acute hyperketonemia on the cerebral uptake of ketone bodies in nondiabetic subjects and IDDM patients. Am. J. Physiol. Endocrinol. Metab. 283, E20-E28. doi: 10.1152/ajpendo.00294.2001

Blomqvist, G., Thorell, J. O., Ingvar, M., Grill, V., Widen, L., and Stone-Elander, S. (1995). Use of R- $\beta$-[1-11C]hydroxybutyrate in PET studies of regional cerebral uptake of ketone bodies in humans. Am. J. Physiol. 269, E948-E959.

Blum-Degen, D., Muller, T., Kuhn, W., Gerlach, M., Przuntek, H., and Riederer, P. (1995). Interleukin-1 $\beta$ and interleukin-6 are elevated in the cerebrospinal fluid of Alzheimer's and de novo Parkinson's disease patients. Neurosci. Lett. 202, 17-20. doi: 10.1016/0304-3940(95)12192-7

Bohnen, N. I., Djang, D. S., Herholz, K., Anzai, Y., and Minoshima, S. (2012). Effectiveness and safety of 18F-FDG PET in the evaluation of dementia: a review of the recent literature. J. Nucl. Med. 53, 59-71. doi: 10.2967/jnumed. 111.096578

Borghammer, P., Hansen, S. B., Eggers, C., Chakravarty, M., Vang, K., Aanerud, J., et al. (2012). Glucose metabolism in small subcortical structures in Parkinson's disease. Acta Neurol. Scand. 125, 303-310. doi: 10.1111/j.1600-0404.2011. 01556.x

Bosco, D., Fava, A., Plastino, M., Montalcini, T., and Pujia, A. (2011). Possible implications of insulin resistance and glucose metabolism in Alzheimer's disease pathogenesis. J. Cell. Mol. Med. 15, 1807-1821. doi: 10.1111/j.15824934.2011.01318.x

Boumezbeur, F., Petersen, K. F., Cline, G. W., Mason, G. F., Behar, K. L., Shulman, G. I., et al. (2010). The contribution of blood lactate to brain energy metabolism in humans measured by dynamic $13 \mathrm{C}$ nuclear magnetic resonance spectroscopy. J. Neurosci. 30, 13983-13991. doi: 10.1523/JNEUROSCI.2040-10. 2010

Bowie, C. R., and Harvey, P. D. (2006). Administration and interpretation of the Trail Making Test. Nat. Protoc. 1, 2277-2281. doi: 10.1038/nprot. 2006.390

Braak, H., Alafuzoff, I., Arzberger, T., Kretzschmar, H., and Del Tredici, K. (2006). Staging of Alzheimer disease-associated neurofibrillary pathology using paraffin sections and immunocytochemistry. Acta Neuropathol. 112, 389-404. doi: 10.1007/s00401-006-0127-z

Braak, H., and Braak, E. (1991). Neuropathological stageing of Alzheimer-related changes. Acta Neuropathol. 82, 239-259. doi: 10.1007/bf00308809

Brant, A. M., Jess, T. J., Milligan, G., Brown, C. M., and Gould, G. W. (1993). Immunological analysis of glucose transporters expressed in different regions of the rat brain and central nervous system. Biochem. Biophys. Res. Commun. 192, 1297-1302. doi: 10.1006/bbrc.1993.1557

Brinton, R. D. (2008a). Estrogen regulation of glucose metabolism and mitochondrial function: therapeutic implications for prevention of Alzheimer's disease. Adv. Drug Deliv. Rev. 60, 1504-1511. doi: 10.1016/j.addr.2008. 06.003 
Brinton, R. D. (2008b). The healthy cell bias of estrogen action: mitochondrial bioenergetics and neurological implications. Trends Neurosci. 31, 529-537. doi: 10.1016/j.tins.2008.07.003

Brown, A. M., and Ransom, B. R. (2007). Astrocyte glycogen and brain energy metabolism. Glia 55, 1263-1271. doi: 10.1002/glia.20557

Burns, J. M., Church, J. A., Johnson, D. K., Xiong, C., Marcus, D., Fotenos, A. F., et al. (2005). White matter lesions are prevalent but differentially related with cognition in aging and early Alzheimer disease. Arch. Neurol. 62, 1870-1876. doi: 10.1001/archneur.62.12.1870

Cahill, G. F. Jr. (2006). Fuel metabolism in starvation. Annu. Rev. Nutr. 26, 1-22. doi: 10.1146/annurev.nutr.26.061505.111258

Cai, W., Sakaguchi, M., Kleinridders, A., Gonzalez-Del Pino, G., Dreyfuss, J. M., O'neill, B. T., et al. (2017). Domain-dependent effects of insulin and IGF-1 receptors on signalling and gene expression. Nat. Commun. 8:14892. doi: 10.1038/ncomms14892

Cardoso, S. M., Proenca, M. T., Santos, S., Santana, I., and Oliveira, C. R. (2004). Cytochrome c oxidase is decreased in Alzheimer's disease platelets. Neurobiol. Aging 25, 105-110. doi: 10.1016/s0197-4580(03)00033-2

Castellano, C. A., Nugent, S., Paquet, N., Tremblay, S., Bocti, C., Lacombe, G., et al. (2015). Lower brain 18F-fluorodeoxyglucose uptake but normal $11 \mathrm{C}$-acetoacetate metabolism in mild Alzheimer's disease dementia. J. Alzheimers Dis. 43, 1343-1353. doi: 10.3233/JAD-141074

Chaturvedi, R. K., and Beal, M. F. (2013). Mitochondrial diseases of the brain. Free Radic. Biol. Medi.ine 63, 1-29. doi: 10.1016/j.freeradbiomed.2013. 03.018

Cheng, G., Huang, C., Deng, H., and Wang, H. (2012). Diabetes as a risk factor for dementia and mild cognitive impairment: a meta-analysis of longitudinal studies. Intern. Med. J. 42, 484-491. doi: 10.1111/j.1445-5994.2012. 02758.x

Chen, Z., and Zhong, C. (2013). Decoding Alzheimer's disease from perturbed cerebral glucose metabolism: implications for diagnostic and therapeutic strategies. Prog. Neurobiol. 108, 21-43. doi: 10.1016/j.pneurobio.2013. 06.004

Cholerton, B., Baker, L. D., and Craft, S. (2011). Insulin resistance and pathological brain ageing. Diabet. Med. 28, 1463-1475. doi: 10.1111/j.1464-5491.2011. 03464.x

Cholerton, B., Baker, L. D., and Craft, S. (2013). Insulin, cognition, and dementia. Eur. J. Pharmacol. 719, 170-179. doi: 10.1016/j.ejphar.2013.08.008

Cistaro, A., Valentini, M. C., Chiò, A., Nobili, F., Calvo, A., Moglia, C., et al. (2012). Brain hypermetabolism in amyotrophic lateral sclerosis: a FDG PET study in ALS of spinal and bulbar onset. Eur. J. Nucl. Med. Mol. Imaging 39, 251-259. doi: 10.1007/s00259-011-1979-6

Claxton, A., Baker, L. D., Hanson, A., Trittschuh, E. H., Cholerton, B., Morgan, A., et al. (2015). Long-acting intranasal insulin detemir improves cognition for adults with mild cognitive impairment or early-stage Alzheimer's disease dementia. J. Alzheimers Dis. 44, 897-906. doi: 10.3233/JAD141791

Claxton, A., Baker, L. D., Wilkinson, C. W., Trittschuh, E. H., Chapman, D., Watson, G. S., et al. (2013). Sex and ApoE genotype differences in treatment response to two doses of intranasal insulin in adults with mild cognitive impairment or Alzheimer's disease. J. Alzheimers Dis. 35, 789-797. doi: 10.3233/JAD-122308

Convit, A., Wolf, O. T., Tarshish, C., and de Leon, M. J. (2003). Reduced glucose tolerance is associated with poor memory performance and hippocampal atrophy among normal elderly. Proc. Natl. Acad. Sci. U S A 100, 2019-2022. doi: 10.1073/pnas.0336073100

Cook, D. G., Leverenz, J. B., McMillan, P. J., Kulstad, J. J., Ericksen, S., Roth, R. A., et al. (2003). Reduced hippocampal insulin-degrading enzyme in late-onset Alzheimer's disease is associated with the apolipoprotein E- $\epsilon 4$ allele. Am. J. Pathol. 162, 313-319. doi: 10.1016/s0002-9440(10)63822-9

Cooper, G. J., Day, A. J., Willis, A. C., Roberts, A. N., Reid, K. B., and Leighton, B. (1989). Amylin and the amylin gene: structure, function and relationship to islet amyloid and to diabetes mellitus. Biochim. Biophys. Acta 1014, 247-258. doi: 10.1016/0167-4889(89)90220-6

Correia, S. C., Santos, R. X., Carvalho, C., Cardoso, S., Candeias, E., Santos, M. S., et al. (2012). Insulin signaling, glucose metabolism and mitochondria: major players in Alzheimer's disease and diabetes interrelation. Brain Res. 1441, 64-78. doi: 10.1016/j.brainres.2011.12.063
Craft, S. (2007). Insulin resistance and Alzheimer's disease pathogenesis: potential mechanisms and implications for treatment. Curr. Alzheimer Res. 4, 147-152. doi: 10.2174/156720507780362137

Craft, S. (2009). The role of metabolic disorders in Alzheimer disease and vascular dementia. Arch. Neurol. 66, 300-305. doi: 10.1001/archneurol. 2009.27

Craft, S., Asthana, S., Cook, D. G., Baker, L. D., Cherrier, M., Purganan, K. et al. (2003). Insulin dose-response effects on memory and plasma amyloid precursor protein in Alzheimer's disease: interactions with apolipoprotein E genotype. Psychoneuroendocrinology 28, 809-822. doi: 10.1016/s03064530(02)00087-2

Craft, S., Asthana, S., Newcomer, J. W., Wilkinson, C. W., Matos, I. T., Baker, L. D., et al. (1999). Enhancement of memory in Alzheimer disease with insulin and somatostatin, but not glucose. Arch. Gen. Psychiatry 56, 1135-1140. doi: 10.1001/archpsyc.56.12.1135

Craft, S., Baker, L. D., Montine, T. J., Minoshima, S., Watson, G. S., Claxton, A., et al. (2012). Intranasal insulin therapy for alzheimer disease and amnestic mild cognitive impairment: a pilot clinical trial. Arch. Neurol. 69, 29-38. doi: 10.1001/archneurol.2011.233

Craft, S., Cholerton, B., and Baker, L. D. (2013). Insulin and Alzheimer's disease: untangling the web. J. Alzheimers Dis. 33, S263-S275. doi: 10.3233/JAD-2012129042

Craft, S., Newcomer, J., Kanne, S., Dagogo-Jack, S., Cryer, P., Sheline, Y., et al. (1996). Memory improvement following induced hyperinsulinemia in Alzheimer's disease. Neurobiol. Aging 17, 123-130. doi: 10.1016/01974580(95)02002-0

Craft, S., Peskind, E., Schwartz, M. W., Schellenberg, G. D., Raskind, M., and Porte, D. Jr. (1998). Cerebrospinal fluid and plasma insulin levels in Alzheimer's disease: relationship to severity of dementia and apolipoprotein E genotype. Neurology 50, 164-168. doi: 10.1212/wnl.50.1.164

Craft, S., and Watson, G. S. (2004). Insulin and neurodegenerative disease: shared and specific mechanisms. Lancet Neurol. 3, 169-178. doi: 10.1016/s14744422(04)00681-7

Cui, H., Kong, Y., and Zhang, H. (2012). Oxidative stress, mitochondrial dysfunction, and aging. J. Signal Transduct. 2012:646354. doi: 10.1155/2012/646354

Cunnane, S. C., Courchesne-Loyer, A., St-Pierre, V., Vandenberghe, C., Pierotti, T., Fortier, M., et al. (2016). Can ketones compensate for deteriorating brain glucose uptake during aging? Implications for the risk and treatment of Alzheimer's disease. Ann. N Y Acad. Sci. 1367, 12-20. doi: 10.1111/nyas. 12999

Cunnane, S., Nugent, S., Roy, M., Courchesne-Loyer, A., Croteau, E., Tremblay, S., et al. (2011). Brain fuel metabolism, aging and Alzheimer's disease. Nutrition 27, 3-20. doi: 10.1016/j.nut.2010.07.021

De Felice, F. G., and Ferreira, S. T. (2014). Inflammation, defective insulin signaling, and mitochondrial dysfunction as common molecular denominators connecting type 2 diabetes to Alzheimer disease. Diabetes 63, 2262-2272. doi: $10.2337 / \mathrm{db} 13-1954$

De Felice, F. G., and Lourenco, M. V. (2015). Brain metabolic stress and neuroinflammation at the basis of cognitive impairment in Alzheimer's disease. Front. Aging Neurosci. 7:94. doi: 10.3389/fnagi.2015.00094

De Felice, F. G., Vieira, M. N., Bomfim, T. R., Decker, H., Velasco, P. T., Lambert, M. P., et al. (2009). Protection of synapses against Alzheimer'slinked toxins: insulin signaling prevents the pathogenic binding of $A \beta$ oligomers. Proc. Natl. Acad. Sci. U S A 106, 1971-1976. doi: 10.1073/pnas.0809 158106

DeFronzo, R. A. (2010). Insulin resistance, lipotoxicity, type 2 diabetes and atherosclerosis: the missing links. The Claude Bernard Lecture 2009. Diabetologia 53, 1270-1287. doi: 10.1007/s00125-010-1684-1

DeFronzo, R. A., Bonadonna, R. C., and Ferrannini, E. (1992). Pathogenesis of NIDDM. A balanced overview. Diabetes Care 15, 318-368. doi: $10.2337 /$ diacare.15.3.318

DeFronzo, R. A., and Ferrannini, E. (1991). Insulin resistance. A multifaceted syndrome responsible for NIDDM, obesity, hypertension, dyslipidemia, and atherosclerotic cardiovascular disease. Diabetes Care 14, 173-194. doi: 10.2337/diacare.14.3.173

Despa, S., Margulies, K. B., Chen, L., Knowlton, A. A., Havel, P. J., Taegtmeyer, H., et al. (2012). Hyperamylinemia contributes to cardiac dysfunction in obesity 
and diabetes: a study in humans and rats. Circ. Res. 110, 598-608. doi: 10.1161/CIRCRESAHA.111.258285

Devi, L., Alldred, M. J., Ginsberg, S. D., and Ohno, M. (2012). Mechanisms underlying insulin deficiency-induced acceleration of $\beta$-amyloidosis in a mouse model of Alzheimer's disease. PLoS One 7:e32792. doi: 10.1371/journal.pone. 0032792

Devraj, K., Klinger, M. E., Myers, R. L., Mokashi, A., Hawkins, R. A., and Simpson, I. A. (2011). GLUT-1 glucose transporters in the blood-brain barrier: differential phosphorylation. J. Neurosci. Res. 89, 1913-1925. doi: 10.1002/jnr. 22738

Di Paolo, G., and Kim, T. W. (2011). Linking lipids to Alzheimer's disease: cholesterol and beyond. Nat. Rev. Neurosci. 12, 284-296. doi: 10.1038/ nrn3012

Ding, F., Yao, J., Rettberg, J. R., Chen, S., and Brinton, R. D. (2013a). Early decline in glucose transport and metabolism precedes shift to ketogenic system in female aging and Alzheimer's mouse brain: implication for bioenergetic intervention. PLoS One 8:e79977. doi: 10.1371/journal.pone. 0079977

Ding, F., Yao, J., Zhao, L., Mao, Z., Chen, S., and Brinton, R. D. (2013b). Ovariectomy induces a shift in fuel availability and metabolism in the hippocampus of the female transgenic model of familial Alzheimer's. PLoS One 8:e59825. doi: 10.1371/journal.pone.0059825

Doody, R. S., Thomas, R. G., Farlow, M., Iwatsubo, T., Vellas, B., Joffe, S., et al. (2014). Phase 3 trials of solanezumab for mild-to-moderate Alzheimer's disease. N. Engl. J. Med. 370, 311-321. doi: 10.1056/NEJMoa 1312889

Dou, J. T., Chen, M., Dufour, F., Alkon, D. L., and Zhao, W. Q. (2005). Insulin receptor signaling in long-term memory consolidation following spatial learning. Learn. Mem. 12, 646-655. doi: 10.1101/lm.88005

Duarte, A. I., Moreira, P. I., and Oliveira, C. R. (2012). Insulin in central nervous system: more than just a peripheral hormone. J. Aging Res. 2012:384017. doi: 10.1155/2012/384017

Edland, S. D., Silverman, J. M., Peskind, E. R., Tsuang, D., Wijsman, E., and Morris, J. C. (1996). Increased risk of dementia in mothers of Alzheimer's disease cases: evidence for maternal inheritance. Neurology 47, 254-256. doi: 10.1212/WNL.47.1.254

El Messari, S., Leloup, C., Quignon, M., Brisorgueil, M. J., Penicaud, L., and Arluison, M. (1998). Immunocytochemical localization of the insulin-responsive glucose transporter 4 (Glut4) in the rat central nervous system. J. Comp. Neurol. 399, 492-512. doi: 10.1002/(sici)10969861(19981005)399:4<492::aid-cne4>3.0.co;2-x

Farris, W., Mansourian, S., Chang, Y., Lindsley, L., Eckman, E. A., Frosch, M. P., et al. (2003). Insulin-degrading enzyme regulates the levels of insulin, amyloid $\beta$-protein, and the $\beta$-amyloid precursor protein intracellular domain in vivo. Proc. Natl. Acad. Sci. U S A 100, 4162-4167. doi: 10.1073/pnas.023 0450100

Festa, A., D’agostino, R. Jr., Howard, G., Mykkänen, L., Tracy, R. P., and Haffner, S. M. (2000). Chronic subclinical inflammation as part of the insulin resistance syndrome: the Insulin Resistance Atherosclerosis Study (IRAS). Circulation 102, 42-47. doi: 10.1161/01.cir.102.1.42

Figlewicz, D. P., Szot, P., Israel, P. A., Payne, C., and Dorsa, D. M. (1993). Insulin reduces norepinephrine transporter mRNA in vivo in rat locus coeruleus. Brain Res. 602, 161-164. doi: 10.1016/0006-8993(93)90258-o

Fratiglioni, L., Ahlbom, A., Viitanen, M., and Winblad, B. (1993). Risk factors for late-onset Alzheimer's disease: a population-based, case-control study. Ann Neurol 33, 258-266. doi: 10.1002/ana.410330306

Freiherr, J., Hallschmid, M., Frey, W. H. II, Brunner, Y. F., Chapman, C. D., Holscher, C., et al. (2013). Intranasal insulin as a treatment for Alzheimer's disease: a review of basic research and clinical evidence. CNS Drugs 27, 505-514. doi: 10.1007/s40263-013-0076-8

Fukao, T., Song, X. Q., Mitchell, G. A., Yamaguchi, S., Sukegawa, K., Orii, T., et al. (1997). Enzymes of ketone body utilization in human tissues: protein and messenger RNA levels of succinyl-coenzyme A (CoA):3-ketoacid CoA transferase and mitochondrial and cytosolic acetoacetyl-CoA thiolases. Pediatr. Res. 42, 498-502. doi: 10.1203/00006450-199710000-00013

Garber, A. J., Menzel, P. H., Boden, G., and Owen, O. E. (1974). Hepatic ketogenesis and gluconeogenesis in humans. J. Clin. Invest. 54, 981-989. doi: $10.1172 /$ jci107839
Garwood, C. J., Ratcliffe, L. E., Morgan, S. V., Simpson, J. E., Owens, H., Vazquez-Villaseñor, I., et al. (2015). Insulin and IGF1 signalling pathways in human astrocytes in vitro and in vivo; characterisation, subcellular localisation and modulation of the receptors. Mol. Brain 8:51. doi: 10.1186/s13041-0150138-6

Gasparini, L., Gouras, G. K., Wang, R., Gross, R. S., Beal, M. F., Greengard, P., et al. (2001). Stimulation of $\beta$-amyloid precursor protein trafficking by insulin reduces intraneuronal $\beta$-amyloid and requires mitogen-activated protein kinase signaling. J. Neurosci. 21, 2561-2570.

Genin, E., Hannequin, D., Wallon, D., Sleegers, K., Hiltunen, M., Combarros, O., et al. (2011). APOE and Alzheimer disease: a major gene with semi-dominant inheritance. Mol. Psychiatry 16, 903-907. doi: 10.1038/mp.2011.52

Ghasemi, R., Dargahi, L., Haeri, A., Moosavi, M., Mohamed, Z., and Ahmadiani, A. (2013a). Brain insulin dysregulation: implication for neurological and neuropsychiatric disorders. Mol. Neurobiol. 47, 1045-1065. doi: 10.1007/s12035-013-8404-z

Ghasemi, R., Haeri, A., Dargahi, L., Mohamed, Z., and Ahmadiani, A. (2013b). Insulin in the brain: sources, localization and functions. Mol. Neurobiol. 47, 145-171. doi: 10.1007/s12035-012-8339-9

Gillette-Guyonnet, S., Nourhashemi, F., Andrieu, S., de Glisezinski, I., Ousset, P. J., Riviere, D., et al. (2000). Weight loss in Alzheimer disease. Am. J. Clin. Nutr. 71, 637s-642s.

Gilman, S., Junck, L., Markel, D. S., Koeppe, R. A., and Kluin, K. J. (1990). Cerebral glucose hypermetabolism in Friedreich's ataxia detected with positron emission tomography. Ann. Neurol. 28, 750-757. doi: 10.1002/ana.410 280605

Goldin, A., Beckman, J. A., Schmidt, A. M., and Creager, M. A. (2006). Advanced glycation end products: sparking the development of diabetic vascular injury. Circulation 114, 597-605. doi: 10.1161/circulationaha.106. 621854

Gonzalez, S. V., Nguyen, N. H., Rise, F., and Hassel, B. (2005). Brain metabolism of exogenous pyruvate. J. Neurochem. 95, 284-293. doi: 10.1111/j.1471-4159. 2005.03365.x

Greenwood, C. E., and Winocur, G. (2001). Glucose treatment reduces memory deficits in young adult rats fed high-fat diets. Neurobiol. Learn. Mem. 75, 179-189. doi: 10.1006/nlme.2000.3964

Haier, R. J., Alkire, M. T., White, N. S., Uncapher, M. R., Head, E., Lott, I. T., et al. (2003). Temporal cortex hypermetabolism in Down syndrome prior to the onset of dementia. Neurology 61, 1673-1679. doi: 10.1212/01.wnl.0000098935. 36984.25

Haier, R. J., Head, K., Head, E., and Lott, I. T. (2008). Neuroimaging of individuals with Down's syndrome at-risk for dementia: evidence for possible compensatory events. Neuroimage 39, 1324-1332. doi: 10.1016/j.neuroimage. 2007.09.064

Haj-ali, V., Mohaddes, G., and Babri, S. H. (2009). Intracerebroventricular insulin improves spatial learning and memory in male Wistar rats. Behav. Neurosci. 123, 1309-1314. doi: 10.1037/a0017722

Halestrap, A. P., and Wilson, M. C. (2012). The monocarboxylate transporter family-role and regulation. IUBMB Life 64, 109-119. doi: 10.1002/iub.572

Hardy, J. A., and Higgins, G. A. (1992). Alzheimer's disease: the amyloid cascade hypothesis. Science 256, 184-185. doi: 10.1126/science.1566067

Hardy, J., and Selkoe, D. J. (2002). The amyloid hypothesis of Alzheimer's disease: progress and problems on the road to therapeutics. Science 297, 353-356. doi: 10.1126/science.1072994

Hassing, L. B., Grant, M. D., Hofer, S. M., Pedersen, N. L., Nilsson, S. E., Berg, S., et al. (2004). Type 2 diabetes mellitus contributes to cognitive decline in old age: a longitudinal population-based study. J. Int. Neuropsychol. Soc. 10, 599-607. doi: $10.1017 /$ S1355617704104165

Havrankova, J., Roth, J., and Brownstein, M. (1978a). Insulin receptors are widely distributed in the central nervous system of the rat. Nature 272, 827-829. doi: $10.1038 / 272827 \mathrm{a} 0$

Havrankova, J., Schmechel, D., Roth, J., and Brownstein, M. (1978b). Identification of insulin in rat brain. Proc. Natl. Acad. Sci. U S A 75, 5737-5741. doi: 10.1073/pnas.75.11.5737

Hirvonen, J., Virtanen, K. A., Nummenmaa, L., Hannukainen, J. C., Honka, M. J., Bucci, M., et al. (2011). Effects of insulin on brain glucose metabolism in impaired glucose tolerance. Diabetes 60, 443-447. doi: 10.2337/db 10-0940 
Ho, L., Qin, W., Pompl, P. N., Xiang, Z., Wang, J., Zhao, Z., et al. (2004). Diet-induced insulin resistance promotes amyloidosis in a transgenic mouse model of Alzheimer's disease. FASEB J. 18, 902-904. doi: 10.1096/fj.030978fje

Houten, S. M., and Wanders, R. J. (2010). A general introduction to the biochemistry of mitochondrial fatty acid $\beta$-oxidation. J. Inherit. Metab. Dis. 33, 469-477. doi: 10.1007/s10545-010-9061-2

Howard, R., McShane, R., Lindesay, J., Ritchie, C., Baldwin, A., Barber, R., et al. (2012). Donepezil and memantine for moderate-to-severe Alzheimer's disease. N. Engl. J. Med. 366, 893-903. doi: 10.1056/NEJMoa1106668

Ito, S., Ohtsuki, S., and Terasaki, T. (2006). Functional characterization of the brain-to-blood efflux clearance of human amyloid- $\beta$ peptide (1-40) across the rat blood-brain barrier. Neurosci. Res. 56, 246-252. doi: 10.1016/j.neures.2006. 07.006

Jackson, K., Barisone, G. A., Diaz, E., Jin, L. W., DeCarli, C., and Despa, F. (2013). Amylin deposition in the brain: a second amyloid in Alzheimer disease? Ann. Neurol. 74, 517-526. doi: 10.1002/ana.23956

Johnson, D. K., Wilkins, C. H., and Morris, J. C. (2006). Accelerated weight loss may precede diagnosis in Alzheimer disease. Arch. Neurol. 63, 1312-1317. doi: 10.1001/archneur.63.9.1312

Johri, A., and Beal, M. F. (2012). Mitochondrial dysfunction in neurodegenerative diseases. J. Pharmacol. Exp. Ther. 342, 619-630. doi: 10.1124/jpet.112. 192138

Kadish, I., Thibault, O., Blalock, E. M., Chen, K. C., Gant, J. C., Porter, N. M., et al. (2009). Hippocampal and cognitive aging across the lifespan: a bioenergetic shift precedes and increased cholesterol trafficking parallels memory impairment. J. Neurosci. 29, 1805-1816. doi: 10.1523/JNEUROSCI. 4599-08.2009

Kamagate, A., Qu, S., Perdomo, G., Su, D., Kim, D. H., Slusher, S., et al. (2008). FoxO1 mediates insulin-dependent regulation of hepatic VLDL production in mice. J. Clin. Invest. 118, 2347-2364. doi: 10.1172/JCI32914

Karch, C. M., Jeng, A. T., Nowotny, P., Cady, J., Cruchaga, C., and Goate, A. M. (2012). Expression of novel Alzheimer's disease risk genes in control and Alzheimer's disease brains. PLoS One 7:e50976. doi: 10.1371/journal.pone. 0050976

Katakam, P. V. G., Snipes, J. A., Steed, M. M., and Busija, D. W. (2012). Insulin-induced generation of reactive oxygen species and uncoupling of nitric oxide synthase underlie the cerebrovascular insulin resistance in obese rats. J. Cereb. Blood Flow Metab. 32, 792-804. doi: 10.1038/jcbfm. 2011.181

Kern, W., Peters, A., Fruehwald-Schultes, B., Deininger, E., Born, J., and Fehm, H. L. (2001). Improving influence of insulin on cognitive functions in humans. Neuroendocrinology 74, 270-280. doi: 10.1159/000 054694

Kerti, L., Witte, A. V., Winkler, A., Grittner, U., Rujescu, D., and Floel, A. (2013). Higher glucose levels associated with lower memory and reduced hippocampal microstructure. Neurology 81, 1746-1752. doi: 10.1212/01.WNL.0000435561. 00234.ee

Ketterer, C., Tschritter, O., Preissl, H., Heni, M., Häring, H.-U., and Fritsche, A. (2011). Insulin sensitivity of the human brain. Diabetes Res. Clin. Pract. 93, S47-S51. doi: 10.1016/S0168-8227(11)70013-4

Khansari, N., Shakiba, Y., and Mahmoudi, M. (2009). Chronic inflammation and oxidative stress as a major cause of age-related diseases and cancer. Recent Pat. Inflamm. Allergy Drug Discov. 3, 73-80. doi: 10.2174/1872213097 87158371

Kim, J. A., Wei, Y., and Sowers, J. R. (2008). Role of mitochondrial dysfunction in insulin resistance. Circ. Res. 102, 401-414. doi: 10.1161/CIRCRESAHA.107. 165472

Kleinridders, A. (2016). Deciphering brain insulin receptor and insulin-like growth factor 1 receptor signalling. J. Neuroendocrinol. 28:11. doi: 10.1111/jne. 12433

Kleinridders, A., Ferris, H. A., Cai, W., and Kahn, C. R. (2014). Insulin action in brain regulates systemic metabolism and brain function. Diabetes 63, 2232-2243. doi: 10.2337/db14-0568

Kopf, S. R., and Baratti, C. M. (1999). Effects of posttraining administration of insulin on retention of a habituation response in mice: participation of a central cholinergic mechanism. Neurobiol. Learn. Mem. 71, 50-61. doi: 10.1006/nlme. 1998.3831
Kubaszek, A., Pihlajamaki, J., Komarovski, V., Lindi, V., Lindström, J., Eriksson, J., et al. (2003). Promoter polymorphisms of the TNF- $\alpha$ (G-308A) and IL-6 (C$174 \mathrm{G})$ genes predict the conversion from impaired glucose tolerance to type 2 diabetes: the Finnish Diabetes Prevention Study. Diabetes 52, 1872-1876. doi: $10.2337 /$ diabetes.52.7.1872

Kurochkin, I. V., and Goto, S. (1994). Alzheimer's $\beta$-amyloid peptide specifically interacts with and is degraded by insulin degrading enzyme. FEBS Lett. 345, 33-37. doi: 10.1016/0014-5793(94)00387-4

Lee, J. (2013). Adipose tissue macrophages in the development of obesity-induced inflammation, insulin resistance and type 2 diabetes. Arch. Pharm. Res. 36, 208-222. doi: 10.1007/s12272-013-0023-8

Lee, C. C., Kuo, Y. M., Huang, C. C., and Hsu, K. S. (2009). Insulin rescues amyloid $\beta$-induced impairment of hippocampal long-term potentiation. Neurobiol. Aging 30, 377-387. doi: 10.1016/j.neurobiolaging.2007.06.014

Lee, S. J., Lee, W. Y., Kim, Y. K., An, Y. S., Cho, J. W., Choi, J. Y., et al. (2012). Apparent relative hypermetabolism of selective brain areas in Huntington disease and importance of reference region for analysis. Clin. Nucl. Med. 37, 663-668. doi: 10.1097/rlu.0b013e3182478bf2

Lesnefsky, E. J., Moghaddas, S., Tandler, B., Kerner, J., and Hoppel, C. L. (2001). Mitochondrial dysfunction in cardiac disease: ischemia-reperfusion, aging, and heart failure. J. Mol. Cell. Cardiol. 33, 1065-1089. doi: 10.1006/jmcc. 2001.1378

Lim, Y. A., Rhein, V., Baysang, G., Meier, F., Poljak, A., Raftery, M. J., et al. (2010). A $\beta$ and human amylin share a common toxicity pathway via mitochondrial dysfunction. Proteomics 10, 1621-1633. doi: 10.1002/pmic. 200900651

Liu, Y., Liu, F., Grundke-Iqbal, I., Iqbal, K., and Gong, C.-X. (2011). Deficient brain insulin signalling pathway in Alzheimer's disease and diabetes. J. Pathol. 225, 54-62. doi: 10.1002/path.2912

Livingstone, C., Lyall, H., and Gould, G. W. (1995). Hypothalamic GLUT 4 expression: a glucose- and insulin-sensing mechanism? Mol. Cell. Endocrinol. 107, 67-70. doi: 10.1016/0303-7207(94)03423-q

Lowell, B. B., and Shulman, G. I. (2005). Mitochondrial dysfunction and type 2 diabetes. Science 307, 384-387. doi: 10.1126/science.1104343

Lund-Andersen, H. (1979). Transport of glucose from blood to brain. Physiol. Rev. $59,305-352$.

Luo, F., Rustay, N. R., Ebert, U., Hradil, V. P., Cole, T. B., Llano, D. A., et al. (2012). Characterization of 7- and 19-month-old Tg2576 mice using multimodal in vivo imaging: limitations as a translatable model of Alzheimer's disease. Neurobiol. Aging 33, 933-944. doi: 10.1016/j.neurobiolaging.2010. 08.005

Lüth, H. J., Ogunlade, V., Kuhla, B., Kientsch-Engel, R., Stahl, P., Webster, J., et al. (2005). Age- and stage-dependent accumulation of advanced glycation end products in intracellular deposits in normal and Alzheimer's disease brains. Cereb. Cortex 15, 211-220. doi: 10.1093/cercor/bhh123

Madamanchi, N. R., and Runge, M. S. (2007). Mitochondrial dysfunction in atherosclerosis. Circ. Res. 100, 460-473. doi: 10.1161/01.RES.0000258450. 44413.96

Maimaiti, S., Frazier, H. N., Anderson, K. L., Ghoweri, A. O., Brewer, L. D., Porter, N. M., et al. (2017). Novel calcium-related targets of insulin in hippocampal neurons. Neuroscience 364, 130-142. doi: 10.1016/j.neuroscience. 2017.09.019

Mammucari, C., and Rizzuto, R. (2010). Signaling pathways in mitochondrial dysfunction and aging. Mech. Ageing Dev. 131, 536-543. doi: 10.1016/j.mad. 2010.07.003

McDermott, J. R., and Gibson, A. M. (1997). Degradation of Alzheimer's $\beta$-amyloid protein by human and rat brain peptidases: involvement of insulin-degrading enzyme. Neurochem. Res. 22, 49-56. doi: 10.1023/A:10273 25304203

Medina, D., DeToledo-Morrell, L., Urresta, F., Gabrieli, J. D., Moseley, M., Fleischman, D., et al. (2006). White matter changes in mild cognitive impairment and AD: a diffusion tensor imaging study. Neurobiol. Aging 27, 663-672. doi: 10.1016/j.neurobiolaging.2005.03.026

Montgomery, M. K., and Turner, N. (2015). Mitochondrial dysfunction and insulin resistance: an update. Endocr. Connect. 4, R1-R15. doi: 10.1530/ec-140092

Morris, A. (2005). Cerebral ketone body metabolism. J. Inherit. Metab. Dis. 28, 109-121. doi: 10.1007/s10545-005-5518-0 
Mosconi, L. (2005). Brain glucose metabolism in the early and specific diagnosis of Alzheimer's disease. FDG-PET studies in MCI and AD. Eur. J. Nucl. Med. Mol. Imaging 32, 486-510. doi: 10.1007/s00259-005-1762-7

Mosconi, L., Brys, M., Switalski, R., Mistur, R., Glodzik, L., Pirraglia, E., et al. (2007). Maternal family history of Alzheimer's disease predisposes to reduced brain glucose metabolism. Proc. Natl. Acad. Sci. U S A 104, 19067-19072. doi: 10.1073/pnas.0705036104

Mosconi, L., Mistur, R., Switalski, R., Brys, M., Glodzik, L., Rich, K., et al. (2009a). Declining brain glucose metabolism in normal individuals with a maternal history of Alzheimer disease. Neurology 72, 513-520. doi: 10.1212/01.wnl. 0000333247.51383 .43

Mosconi, L., Mistur, R., Switalski, R., Tsui, W. H., Glodzik, L., Li, Y., et al. (2009b). FDG-PET changes in brain glucose metabolism from normal cognition to pathologically verified Alzheimer's disease. Eur. J. Nucl. Med. Mol. Imaging 36, 811-822. doi: 10.1007/s00259-008-1039-z

Mosconi, L., Pupi, A., and De Leon, M. J. (2008). Brain glucose hypometabolism and oxidative stress in preclinical Alzheimer's disease. Ann. N Y Acad. Sci. 1147, 180-195. doi: 10.1196/annals.1427.007

Muniyappa, R., Montagnani, M., Koh, K. K., and Quon, M. J. (2007). Cardiovascular actions of insulin. Endocr. Rev. 28, 463-491. doi: 10.1210/er. 2007-0006

Nagasaka, T., Nagasaka, K., Ohta, E., Shindo, K., Takiyama, Y., Shiozawa, Z., et al. (2011). Cerebral hypermetabolism demonstrated by FDG PET in familial Creutzfeldt-Jakob disease. Clin. Nucl. Med. 36, 725-727. doi: 10.1097/rlu. 0b013e31821a2604

Neumann, K. F., Rojo, L., Navarrete, L. P., Farías, G., Reyes, P., and Maccioni, R. B. (2008). Insulin resistance and Alzheimer's disease: molecular links \& clinical implications. Curr. Alzheimer Res. 5, 438-447. doi: $10.2174 / 156720508785908919$

Novak, V., Milberg, W., Hao, Y., Munshi, M., Novak, P., Galica, A., et al. (2014). Enhancement of vasoreactivity and cognition by intranasal insulin in type 2 diabetes. Diabetes Care 37, 751-759. doi: 10.2337/dc13-1672

Nugent, S., Tremblay, S., Chen, K. W., Ayutyanont, N., Roontiva, A., Castellano, C. A., et al. (2014). Brain glucose and acetoacetate metabolism: a comparison of young and older adults. Neurobiol. Aging 35, 1386-1395. doi: 10.1016/j.neurobiolaging.2013.11.027

Oskarsson, M. E., Paulsson, J. F., Schultz, S. W., Ingelsson, M., Westermark, P., and Westermark, G. T. (2015). In vivo seeding and cross-seeding of localized amyloidosis: a molecular link between type 2 diabetes and Alzheimer disease. Am. J. Pathol. 185, 834-846. doi: 10.1016/j.ajpath.2014. 11.016

Pan, J. W., Rothman, T. L., Behar, K. L., Stein, D. T., and Hetherington, H. P. (2000). Human brain $\beta$-hydroxybutyrate and lactate increase in fasting-induced ketosis. J. Cereb. Blood Flow Metab. 20, 1502-1507. doi: 10.1097/00004647-200010000-00012

Pancani, T., Anderson, K. L., Porter, N. M., and Thibault, O. (2011). Imaging of a glucose analog, calcium and NADH in neurons and astrocytes: dynamic responses to depolarization and sensitivity to pioglitazone. Cell Calcium 50, 548-558. doi: 10.1016/j.ceca.2011.09.002

Park, C. R., Seeley, R. J., Craft, S., and Woods, S. C. (2000). Intracerebroventricular insulin enhances memory in a passive-avoidance task. Physiol. Behav. 68, 509-514. doi: 10.1016/s0031-9384(99)00220-6

Park, L. C., Zhang, H., Sheu, K. F., Calingasan, N. Y., Kristal, B. S., Lindsay, J. G., et al. (1999). Metabolic impairment induces oxidative stress, compromises inflammatory responses, and inactivates a key mitochondrial enzyme in microglia. J. Neurochem. 72, 1948-1958. doi: 10.1046/j.1471-4159. 1999.0721948.x

Parker, W. D. Jr., Filley, C. M., and Parks, J. K. (1990). Cytochrome oxidase deficiency in Alzheimer's disease. Neurology 40, 1302-1303. doi: 10.1212/WNL. 40.8.1302

Pellerin, L., Bouzier-Sore, A. K., Aubert, A., Serres, S., Merle, M., Costalat, R., et al. (2007). Activity-dependent regulation of energy metabolism by astrocytes: an update. Glia 55, 1251-1262. doi: 10.1002/glia. 20528

Pérez, A., Morelli, L., Cresto, J. C., and Castaño, E. M. (2000). Degradation of soluble amyloid $\beta$-peptides 1-40, 1-42, and the Dutch variant 1-40Q by insulin degrading enzyme from Alzheimer disease and control brains. Neurochem. Res. 25, 247-255. doi: 10.1023/A:1007527721160
Piroli, G. G., Grillo, C. A., Reznikov, L. R., Adams, S., McEwen, B. S., Charron, M. J., et al. (2007). Corticosterone impairs insulin-stimulated translocation of GLUT4 in the rat hippocampus. Neuroendocrinology 85, 71-80. doi: $10.1159 / 000101694$

Poisnel, G., Hérard, A. S., El Tannir El Tayara, N., Bourrin, E., Volk, A., Kober, F., et al. (2012). Increased regional cerebral glucose uptake in an APP/PS1 model of Alzheimer's disease. Neurobiol. Aging 33, 1995-2005. doi: 10.1016/j.neurobiolaging.2011.09.026

Pradhan, A. D., Manson, J. E., Rifai, N., Buring, J. E., and Ridker, P. M. (2001). Creactive protein, interleukin 6 and risk of developing type 2 diabetes mellitus. JAMA 286, 327-334. doi: 10.1001/jama.286.3.327

Purdon, A. D., Rosenberger, T. A., Shetty, H. U., and Rapoport, S. I. (2002). Energy consumption by phospholipid metabolism in mammalian brain. Neurochem. Res. 27, 1641-1647. doi: 10.1023/A:1021635027211

Qiu, W. Q., Walsh, D. M., Ye, Z., Vekrellis, K., Zhang, J., Podlisny, M. B., et al. (1998). Insulin-degrading enzyme regulates extracellular levels of amyloid $\beta$ protein by degradation. J. Biol. Chem. 273, 32730-32738. doi: 10.1074/jbc.273. 49.32730

Quarles, R. H., Macklin, W. B., and Morell, P. (2006). Myelin Formation, Structure and Biochemistry. London: Elsevier.

Ramasamy, R., Vannucci, S. J., Yan, S. S., Herold, K., Yan, S. F., and Schmidt, A. M. (2005). Advanced glycation end products and RAGE: a common thread in aging, diabetes, neurodegeneration, and inflammation. Glycobiology 15, 16R-28R. doi: 10.1093/glycob/cwi053

Reagan, L. P., Gorovits, N., Hoskin, E. K., Alves, S. E., Katz, E. B., Grillo, C. A. et al. (2001). Localization and regulation of GLUTx1 glucose transporter in the hippocampus of streptozotocin diabetic rats. Proc. Natl. Acad. Sci. U S A 98, 2820-2825. doi: 10.1073/pnas.051629798

Reaven, G. M. (1983). Insulin resistance in noninsulin-dependent diabetes mellitus. Does it exist and can it be measured? Am. J. Med. 74, 3-17. doi: 10.1016/0002-9343(83)90650-2

Reaven, G. M. (2003). The insulin resistance syndrome. Curr. Atheroscler. Rep. 5, 364-371. doi: 10.1007/s11883-003-0007-0

Reddy, P. H. (2009). Amyloid $\beta$, mitochondrial structural and functional dynamics in Alzheimer's disease. Exp. Neurol. 218, 286-292. doi: 10.1016/j.expneurol. 2009.03.042

Reed, B., Villeneuve, S., Mack, W., DeCarli, C., Chui, H. C., and Jagust, W. (2014). Associations between serum cholesterol levels and cerebral amyloidosis. JAMA Neurol. 71, 195-200. doi: 10.1001/jamaneurol.2013.5390

Reger, M. A., Watson, G. S., Frey, W. H., Baker, L. D., Cholerton, B., Keeling, M. L., et al. (2006). Effects of intranasal insulin on cognition in memory-impaired older adults: Modulation by APOE genotype. Neurobiology of Aging 27, 451-458. doi: 10.1016/j.neurobiolaging.2005.03.016

Reger, M. A., Watson, G. S., Green, P. S., Baker, L. D., Cholerton, B., Fishel, M. A., et al. (2008). Intranasal insulin administration dose-dependently modulates verbal memory and plasma amyloid- $\beta$ in memory-impaired older adults. J. Alzheimers Dis. 13, 323-331. doi: 10.3233/jad-200813309

Reiman, E. M., Caselli, R. J., Yun, L. S., Chen, K., Bandy, D., Minoshima, S., et al. (1996). Preclinical evidence of Alzheimer's disease in persons homozygous for the epsilon 4 allele for apolipoprotein E. N. Engl. J. Med. 334, 752-758. doi: 10.1056/nejm199603213341202

Reitz, C. (2013). Dyslipidemia and the risk of Alzheimer's disease. Curr. Atheroscler. Rep. 15:307. doi: 10.1007/s11883-012-0307-3

Robinson, P. J., Noronha, J., DeGeorge, J. J., Freed, L. M., Nariai, T., and Rapoport, S. I. (1992). A quantitative method for measuring regional in vivo fatty-acid incorporation into and turnover within brain phospholipids: review and critical analysis. Brain Res. Brain Res. Rev. 17, 187-214. doi: 10.1016/01650173(92)90016-f

Roden, M., Perseghin, G., Petersen, K. F., Hwang, J. H., Cline, G. W., Gerow, K., et al. (1996). The roles of insulin and glucagon in the regulation of hepatic glycogen synthesis and turnover in humans. J. Clin. Invest. 97, 642-648. doi: $10.1172 /$ jcil1 18460

Rojas, S., Herance, J. R., Gispert, J. D., Abad, S., Torrent, E., Jiménez, X., et al. (2013). In vivo evaluation of amyloid deposition and brain glucose metabolism of 5XFAD mice using positron emission tomography. Neurobiol. Aging 34, 1790-1798. doi: 10.1016/j.neurobiolaging.2012. 12.027 
Roriz-Filho, J. S., Sá-Roriz, T. M., Rosset, I., Camozzato, A. L., Santos, A. C., Chaves, M. L. F., et al. (2009). (Pre)diabetes, brain aging and cognition. Biochim. Biophys. Acta 1792, 432-443. doi: 10.1016/j.bbadis.2008.12.003

Roy, M., Nugent, S., Tremblay-Mercier, J., Tremblay, S., Courchesne-Loyer, A., Beaudoin, J.-F., et al. (2012). The ketogenic diet increases brain glucose and ketone uptake in aged rats A dual tracer PET and volumetric MRI study. Brain Res. 1488, 14-23. doi: 10.1016/j.brainres.2012.10.008

Ryu, J. K., and McLarnon, J. G. (2009). A leaky blood-brain barrier, fibrinogen infiltration and microglial reactivity in inflamed Alzheimer's disease brain. J. Cell. Mol. Med. 13, 2911-2925. doi: 10.1111/j.1582-4934.2008. 00434.x

Salloway, S., Sperling, R., Fox, N. C., Blennow, K., Klunk, W., Raskind, M., et al. (2014). Two phase 3 trials of bapineuzumab in mild-to-moderate Alzheimer's disease. N. Engl. J. Med. 370, 322-333. doi: 10.1056/NEJMoa1304839

Saltiel, A. R., and Kahn, C. R. (2001). Insulin signalling and the regulation of glucose and lipid metabolism. Nature 414, 799-806. doi: 10.1038/ 414799a

Sanchez-Mejia, R. O., Newman, J. W., Toh, S., Yu, G. Q., Zhou, Y., Halabisky, B., et al. (2008). Phospholipase A2 reduction ameliorates cognitive deficits in a mouse model of Alzheimer's disease. Nat. Neurosci. 11, 1311-1318. doi: $10.1038 / \mathrm{nn} .2213$

Sasaki, N., Fukatsu, R., Tsuzuki, K., Hayashi, Y., Yoshida, T., Fujii, N., et al. (1998). Advanced glycation end products in Alzheimer's disease and other neurodegenerative diseases. Am. J. Pathol. 153, 1149-1155. doi: 10.1016/S00029440(10)65659-3

Savage, D. B., Petersen, K. F., and Shulman, G. I. (2007). Disordered lipid metabolism and the pathogenesis of insulin resistance. Physiol. Rev. 87, 507-520. doi: 10.1152/physrev.00024.2006

Scheff, S. W., Price, D. A., Schmitt, F. A., and Mufson, E. J. (2006). Hippocampal synaptic loss in early Alzheimer's disease and mild cognitive impairment. Neurobiol. Aging 27, 1372-1384. doi: 10.1016/j.neurobiolaging.2005. 09.012

Schiöth, H. B., Craft, S., Brooks, S. J., Frey, W. H. II, and Benedict, C. (2012). Brain insulin signaling and Alzheimer's disease: current evidence and future directions. Mol. Neurobiol. 46, 4-10. doi: 10.1007/s12035-011-8229-6

Schneider, L. S., Dagerman, K. S., Higgins, J. P., and McShane, R. (2011a). Lack of evidence for the efficacy of memantine in mild Alzheimer disease. Arch. Neurol. 68, 991-998. doi: 10.1001/archneurol.2011.69

Schneider, L. S., Insel, P. S., and Weiner, M. W. (2011b). Treatment with cholinesterase inhibitors and memantine of patients in the Alzheimer's disease neuroimaging initiative. Arch. Neurol. 68, 58-66. doi: 10.1001/archneurol. 2010.343

Schönfeld, P., and Reiser, G. (2013). Why does brain metabolism not favor burning of fatty acids to provide energy? Reflections on disadvantages of the use of free fatty acids as fuel for brain. J. Cereb. Blood Flow Metab. 33, 1493-1499. doi: $10.1038 /$ jcbfm. 2013.128

Schulingkamp, R. J., Pagano, T. C., Hung, D., and Raffa, R. B. (2000). Insulin receptors and insulin action in the brain: review and clinical implications. Neurosci. Biobehav. Rev. 24, 855-872. doi: 10.1016/s0149-7634(00)00040-3

Schwartz, M., and Baruch, K. (2014). The resolution of neuroinflammation in neurodegeneration: leukocyte recruitment via the choroid plexus. EMBO J. 33, 7-22. doi: 10.1002/embj.201386609

Schwartz, M. W., Figlewicz, D. F., Kahn, S. E., Baskin, D. G., Greenwood, M. R., and Porte, D. Jr. (1990). Insulin binding to brain capillaries is reduced in genetically obese, hyperinsulinemic Zucker rats. Peptides 11, 467-472. doi: 10.1016/0196-9781(90)90044-6

Selkoe, D. J. (1996). Amyloid $\beta$-protein and the genetics of Alzheimer's disease. J. Biol. Chem. 271, 18295-18298. doi: 10.1074/jbc.271.31.18295

Selkoe, D. J. (2002). Alzheimer's disease is a synaptic failure. Science 298, 789-791. doi: 10.1126/science.1074069

Shah, K., Desilva, S., and Abbruscato, T. (2012). The role of glucose transporters in brain disease: diabetes and Alzheimer's Disease. Int. J. Mol. Sci. 13, 12629-12655. doi: 10.3390/ijms131012629

Shulman, G. I., Rothman, D. L., Jue, T., Stein, P., DeFronzo, R. A., and Shulman, R. G. (1990). Quantitation of muscle glycogen synthesis in normal subjects and subjects with non-insulin-dependent diabetes by $13 \mathrm{C}$ nuclear magnetic resonance spectroscopy. N. Engl. J. Med. 322, 223-228. doi: 10.1056/nejm199001253220403
Sims, N. R., Finegan, J. M., Blass, J. P., Bowen, D. M., and Neary, D. (1987). Mitochondrial function in brain tissue in primary degenerative dementia. Brain Res. 436, 30-38. doi: 10.1016/0006-8993(87)91553-8

Singh, R., Barden, A., Mori, T., and Beilin, L. (2001). Advanced glycation endproducts: a review. Diabetologia 44, 129-146. doi: 10.1007/s001250051591

Skeberdis, V. A., Lan, J., Zheng, X., Zukin, R. S., and Bennett, M. V. (2001). Insulin promotes rapid delivery of $\mathrm{N}$-methyl-D- aspartate receptors to the cell surface by exocytosis. Proc. Natl. Acad. Sci. U S A 98, 3561-3566. doi: 10.1073/pnas. 051634698

Small, G. W., Ercoli, L. M., Silverman, D. H., Huang, S. C., Komo, S., Bookheimer, S. Y., et al. (2000). Cerebral metabolic and cognitive decline in persons at genetic risk for Alzheimer's disease. Proc. Natl. Acad. Sci. U S A 97, 6037-6042. doi: 10.1073/pnas.090106797

Sperling, R. A., Aisen, P. S., Beckett, L. A., Bennett, D. A., Craft, S., Fagan, A. M., et al. (2011). Toward defining the preclinical stages of Alzheimer's disease: recommendations from the National Institute on Aging-Alzheimer's Association workgroups on diagnostic guidelines for Alzheimer's disease. Alzheimers Dement. 7, 280-292. doi: 10.1016/j.jalz.2011.03.003

Sridhar, G. R., Lakshmi, G., and Nagamani, G. (2015). Emerging links between type 2 diabetes and Alzheimer's disease. World J. Diabetes 6, 744-751. doi: 10.4239/wjd.v6.i5.744

Srikanth, V., Maczurek, A., Phan, T., Steele, M., Westcott, B., Juskiw, D., et al. (2011). Advanced glycation endproducts and their receptor RAGE in Alzheimer's disease. Neurobiol. Aging 32, 763-777. doi: 10.1016/j. neurobiolaging.2009.04.016

Srodulski, S., Sharma, S., Bachstetter, A. B., Brelsfoard, J. M., Pascual, C., Xie, X. S., et al. (2014). Neuroinflammation and neurologic deficits in diabetes linked to brain accumulation of amylin. Mol. Neurodegener. 9:30. doi: 10.1186/17501326-9-30

Starkov, A. A., Fiskum, G., Chinopoulos, C., Lorenzo, B. J., Browne, S. E., Patel, M. S., et al. (2004). Mitochondrial $\alpha$-ketoglutarate dehydrogenase complex generates reactive oxygen species. J. Neurosci. 24, 7779-7788. doi: 10.1523/JNEUROSCI.1899-04.2004

Stockhorst, U., De Fries, D., Steingrueber, H.-J., and Scherbaum, W. A. (2004). Insulin and the CNS: effects on food intake, memory and endocrine parameters and the role of intranasal insulin administration in humans. Physiol. Behav. 83, 47-54. doi: 10.1016/j.physbeh.2004.07.022

Strachan, M. W. (2011). R D Lawrence Lecture 2010. The brain as a target organ in Type 2 diabetes: exploring the links with cognitive impairment and dementia. Diabet. Med. 28, 141-147. doi: 10.1111/j.1464-5491.2010.03199.x

Stranahan, A. M., Norman, E. D., Lee, K., Cutler, R. G., Telljohann, R. S., Egan, J. M., et al. (2008). Diet-induced insulin resistance impairs hippocampal synaptic plasticity and cognition in middle-aged rats. Hippocampus 18, 1085-1088. doi: 10.1002/hipo.20470

Sudoh, S., Frosch, M. P., and Wolf, B. A. (2002). Differential effects of proteases involved in intracellular degradation of amyloid b-protein between detergentsoluble and -insoluble pools in CHO-695 cells. Biochemistry 41, 1091-1099. doi: $10.1021 /$ bi0111931

Sun, G. Y., Shelat, P. B., Jensen, M. B., He, Y., Sun, A. Y., and Simonyi, A. (2010). Phospholipases A2 and inflammatory responses in the central nervous system. Neuromolecular Med. 12, 133-148. doi: 10.1007/s12017-009-8092-Z

Sun, G. Y., Xu, J., Jensen, M. D., and Simonyi, A. (2004). Phospholipase A2 in the central nervous system: implications for neurodegenerative diseases. J. Lipid Res. 45, 205-213. doi: 10.1194/jlr.r300016-jlr200

Swardfager, W., Lanctot, K., Rothenburg, L., Wong, A., Cappell, J., and Herrmann, N. (2010). A meta-analysis of cytokines in Alzheimer's disease. Biol. Psychiatry 68, 930-941. doi: 10.1016/j.biopsych.2010.06.012

Swerdlow, R. H., Burns, J. M., and Khan, S. M. (2010). The Alzheimer's disease mitochondrial cascade hypothesis. J. Alzheimers Dis. 20, S265-S279. doi: 10.3233/JAD-2010-100339

Swerdlow, R. H., and Khan, S. M. (2004). A “mitochondrial cascade hypothesis" for sporadic Alzheimer's disease. Med. Hypotheses 63, 8-20. doi: 10.1016/j. mehy.2003.12.045

Szendroedi, J., Phielix, E., and Roden, M. (2011). The role of mitochondria in insulin resistance and type 2 diabetes mellitus. Nat. Rev. Endocrinol. 8, 92-103. doi: $10.1038 /$ nrendo.2011.138

Takeda, S., Sato, N., Ikimura, K., Nishino, H., Rakugi, H., and Morishita, R. (2013). Increased blood-brain barrier vulnerability to systemic inflammation 
in an Alzheimer disease mouse model. Neurobiol. Aging 34, 2064-2070. doi: 10.1016/j.neurobiolaging.2013.02.010

Tamaki, C., Ohtsuki, S., and Terasaki, T. (2007). Insulin facilitates the hepatic clearance of plasma amyloid $\beta$-peptide $\left(\begin{array}{ll}1 & 40\end{array}\right)$ by intracellular translocation of low-density lipoprotein receptor-related protein 1 (LRP-1) to the plasma membrane in hepatocytes. Mol. Pharmacol. 72, 850-855. doi: 10.1124/mol.107. 036913

Taylor, R. W., and Turnbull, D. M. (2005). Mitochondrial DNA mutations in human disease. Nat. Rev. Genet. 6, 389-402. doi: 10.1038/nrg1606

Tilvis, R. S., Kähönen-Väre, M. H., Jolkkonen, J., Valvanne, J., Pitkala, K. H., and Strandberg, T. E. (2004). Predictors of cognitive decline and mortality of aged people over a 10-year period. J. Gerontol. A Biol. Sci. Med. Sci. 59, 268-274. doi: 10.1093/gerona/59.3.m268

Townsend, M., Mehta, T., and Selkoe, D. J. (2007). Soluble A $\beta$ inhibits specific signal transduction cascades common to the insulin receptor pathway. J. Biol. Chem. 282, 33305-33312. doi: 10.1074/jbc.M610390200

Tremblay, S., Ouellet, R., Bénard, F., and Cunnane, S. C. (2008). Automated synthesis of $11 \mathrm{C}$ - $\beta$-hydroxybutyrate by enzymatic conversion of $11 \mathrm{C}$ acetoacetate using $\beta$-hydroxybutyrate dehydrogenase. J. Labelled Comp. Radiopharm. 51, 242-245. doi: 10.1002/jlcr.1504

Tremblay, S., Ouellet, R., Rodrigue, S., Langlois, R., Bénard, F., and Cunnane, S. C. (2007). Automated synthesis of 11C-acetoacetic acid, a key alternate brain fuel to glucose. Appl. Radiat. Isot. 65, 934-940. doi: 10.1016/j.apradiso.2007. 03.015

Unger, J. W., Livingston, J. N., and Moss, A. M. (1991). Insulin receptors in the central nervous system: localization, signalling mechanisms and functional aspects. Prog. Neurobiol. 36, 343-362. doi: 10.1016/0301-0082(91) 90015-s

Unoki, H., Bujo, H., Yamagishi, S., Takeuchi, M., Imaizumi, T., and Saito, Y. (2007). Advanced glycation end products attenuate cellular insulin sensitivity by increasing the generation of intracellular reactive oxygen species in adipocytes. Diabetes Res. Clin. Pract. 76, 236-244. doi: 10.1016/j.diabres.2006. 09.016

Unoki, H., and Yamagishi, S. (2008). Advanced glycation end products and insulin resistance. Curr. Pharm. Des. 14, 987-989. doi: 10.2174/1381612087 84139747

Vaishnavi, S. N., Vlassenko, A. G., Rundle, M. M., Snyder, A. Z., Mintun, M. A., and Raichle, M. E. (2010). Regional aerobic glycolysis in the human brain. Proc. Natl. Acad. Sci. U S A 107, 17757-17762. doi: 10.1073/pnas.1010459107

Vanhanen, M., Koivisto, K., Kuusisto, J., Mykkänen, L., Helkala, E. L., Hänninen, T., et al. (1998). Cognitive function in an elderly population with persistent impaired glucose tolerance. Diabetes Care 21, 398-402. doi: $10.2337 /$ diacare.21.3.398

Vlassenko, A. G., Vaishnavi, S. N., Couture, L., Sacco, D., Shannon, B. J., Mach, R. H., et al. (2010). Spatial correlation between brain aerobic glycolysis and amyloid- $\beta$ (A $\beta$ ) deposition. Proc. Natl. Acad. Sci. U S A 107, 17763-17767. doi: 10.1073/pnas.1010461107

Wallace, D. C., Fan, W., and Procaccio, V. (2010). Mitochondrial energetics and therapeutics. Annu. Rev. Pathol. 5, 297-348. doi: 10.1146/annurev.pathol.4. 110807.092314

Wallum, B. J., Taborsky, G. J. Jr., Porte, D. Jr., Figlewicz, D. P., Jacobson, L., Beard, J. C., et al. (1987). Cerebrospinal fluid insulin levels increase during intravenous insulin infusions in man. J. Clin. Endocrinol. Metab. 64, 190-194. doi: 10.1210/jcem-64-1-190

Wang, X., Su, B., Lee, H. G., Li, X., Perry, G., Smith, M. A., et al. (2009). Impaired balance of mitochondrial fission and fusion in Alzheimer's disease. J. Neurosci. 29, 9090-9103. doi: 10.1523/JNEUROSCI.1357-09.2009

Wang, X., Su, B., Siedlak, S. L., Moreira, P. I., Fujioka, H., Wang, Y., et al. (2008). Amyloid- $\beta$ overproduction causes abnormal mitochondrial dynamics via differential modulation of mitochondrial fission/fusion proteins. Proc. Natl. Acad. Sci. U S A 105, 19318-19323. doi: 10.1073/pnas. 0804871105

Watson, G. S., and Craft, S. (2006). Insulin resistance, inflammation, and cognition in Alzheimer's disease: lessons for multiple sclerosis. J. Neurol. Sci. 245, 21-33. doi: 10.1016/j.jns.2005.08.017

Wautier, J. L., Zoukourian, C., Chappey, O., Wautier, M. P., Guillausseau, P. J., Cao, R., et al. (1996). Receptor-mediated endothelial cell dysfunction in diabetic vasculopathy. Soluble receptor for advanced glycation end products blocks hyperpermeability in diabetic rats. J. Clin. Invest. 97, 238-243. doi: $10.1172 /$ jci1 18397

Wei, Y. H., and Lee, H. C. (2002). Oxidative stress, mitochondrial DNA mutation, and impairment of antioxidant enzymes in aging. Exp. Biol. Med. (Maywood) 227, 671-682. doi: 10.1177/153537020222700901

Werther, G. A., Hogg, A., Oldfield, B. J., Mckinley, M. J., Figdor, R., Allen, A. M., et al. (1987). Localization and characterization of insulin receptors in rat brain and pituitary gland using in vitro autoradiography and computerized densitometry. Endocrinology 121, 1562-1570. doi: 10.1210/endo-121 $-4-1562$

White, H., Pieper, C., and Schmader, K. (1998). The association of weight change in Alzheimer's disease with severity of disease and mortality: a longitudinal analysis. J. Am. Geriatr. Soc. 46, 1223-1227. doi: 10.1111/j.1532-5415.1998. tb04537.x

Whitmer, R. A., Gustafson, D. R., Barrett-Connor, E., Haan, M. N., Gunderson, E. P., and Yaffe, K. (2008). Central obesity and increased risk of dementia more than three decades later. Neurology 71, 1057-1064. doi: 10.1212/01.wnl.0000306313.89165.ef

Willette, A. A., Bendlin, B. B., Starks, E. J., Birdsill, A. C., Johnson, S. C., Christian, B. T., et al. (2015a). Association of insulin resistance with cerebral glucose uptake in late middle-aged adults at risk for Alzheimer disease. JAMA Neurol. 72, 1013-1020. doi: 10.1001/jamaneurol. 2015.0613

Willette, A. A., Modanlo, N., and Kapogiannis, D. (2015b). Insulin resistance predicts medial temporal hypermetabolism in mild cognitive impairment conversion to Alzheimer disease. Diabetes 64, 1933-1940. doi: 10.2337/db141507

Woods, S. C., Seeley, R. J., Baskin, D. G., and Schwartz, M. W. (2003). Insulin and the blood-brain barrier. Curr. Pharm. Des. 9, 795-800. doi: $10.2174 / 1381612033455323$

Wyss-Coray, T., and Rogers, J. (2012). Inflammation in Alzheimer disease-a brief review of the basic science and clinical literature. Cold Spring Harb. Perspect. Med. 2:a006346. doi: 10.1101/cshperspect.a006346

Yaffe, K., Blackwell, T., Kanaya, A. M., Davidowitz, N., Barrett-Connor, E., and Krueger, K. (2004). Diabetes, impaired fasting glucose, and development of cognitive impairment in older women. Neurology 63, 658-663. doi: 10.1212/01. WNL.0000134666.64593.ba

Yaffe, K., Blackwell, T., Whitmer, R. A., Krueger, K., and Barrett Connor, E. (2006). Glycosylated hemoglobin level and development of mild cognitive impairment or dementia in older women. J. Nutr. Health Aging 10, 293-295.

Yamagishi, S., Maeda, S., Matsui, T., Ueda, S., Fukami, K., and Okuda, S. (2012). Role of advanced glycation end products (AGEs) and oxidative stress in vascular complications in diabetes. Biochim. Biophys. Acta 1820, 663-671. doi: 10.1016/j.bbagen.2011.03.014

Yao, J., and Brinton, R. D. (2011). Targeting mitochondrial bioenergetics for Alzheimer's prevention and treatment. Curr. Pharm. Des. 17, 3474-3479. doi: $10.2174 / 138161211798072517$

Yao, J., and Brinton, R. D. (2012). Estrogen regulation of mitochondrial bioenergetics: implications for prevention of Alzheimer's disease. Adv. Pharmacol. 64, 327-371. doi: 10.1016/b978-0-12-394816-8. 00010-6

Yao, J., Hamilton, R. T., Cadenas, E., and Brinton, R. D. (2010). Decline in mitochondrial bioenergetics and shift to ketogenic profile in brain during reproductive senescence. Biochim. Biophys. Acta 1800, 1121-1126. doi: 10.1016/j.bbagen.2010.06.002

Yao, J., Irwin, R., Chen, S., Hamilton, R., Cadenas, E., and Brinton, R. D. (2012). Ovarian hormone loss induces bioenergetic deficits and mitochondrial $\beta$ amyloid. Neurobiol. Aging 33, 1507-1521. doi: 10.1016/j.neurobiolaging.2011. 03.001

Yao, J., Irwin, R. W., Zhao, L., Nilsen, J., Hamilton, R. T., and Brinton, R. D. (2009). Mitochondrial bioenergetic deficit precedes Alzheimer's pathology in female mouse model of Alzheimer's disease. Proc. Natl. Acad. Sci. U S A 106, 14670-14675. doi: 10.1073/pnas.0903563106

Yao, J., Rettberg, J. R., Klosinski, L. P., Cadenas, E., and Brinton, R. D. (2011). Shift in brain metabolism in late onset alzheimer's disease: implications for biomarkers and therapeutic interventions. Mol. Aspects Med. 32, 247-257. doi: 10.1016/j.mam.2011.10.005 
Yan, L. M., Velkova, A., and Kapurniotu, A. (2014). Molecular characterization of the hetero-assembly of $\beta$-amyloid peptide with islet amyloid polypeptide. Curr. Pharm. Des. 20, 1182-1191. doi: 10.2174/138161281131 99990064

Zhang, Y., Zhou, B., Deng, B., Zhang, F., Wu, J., Wang, Y., et al. (2013). Amyloid$\beta$ induces hepatic insulin resistance in vivo via JAK2. Diabetes 62, 1159-1166. doi: $10.2337 / \mathrm{db} 12-0670$

Zhao, W. Q., and Alkon, D. L. (2001). Role of insulin and insulin receptor in learning and memory. Mol. Cell. Endocrinol. 177, 125-134. doi: 10.1016/s03037207(01)00455-5

Zhao, W.-Q., Chen, H., Quon, M. J., and Alkon, D. L. (2004). Insulin and the insulin receptor in experimental models of learning and memory. Eur. J. Pharmacol. 490, 71-81. doi: 10.1016/j.ejphar.2004.02.045

Zhao, W., Chen, H., Xu, H., Moore, E., Meiri, N., Quon, M. J., et al. (1999). Brain insulin receptors and spatial memory. Correlated changes in gene expression, tyrosine phosphorylation, and signaling molecules in the hippocampus of water maze trained rats. J. Biol. Chem. 274, 34893-34902. doi: 10.1074/jbc.274.49. 34893

Zhu, D., Lai, Y., Shelat, P. B., Hu, C., Sun, G. Y., and Lee, J. C. (2006). Phospholipases A2 mediate amyloid- $\beta$ peptide-induced mitochondrial dysfunction. J. Neurosci. 26, 11111-11119. doi: 10.1523/jneurosci.350506.2006
Zhao, N., Liu, C. C., Van Ingelgom, A. J., Martens, Y. A., Linares, C., Knight, J. A., et al. (2017). Apolipoprotein E4 impairs neuronal insulin signaling by trapping insulin receptor in the endosomes. Neuron 96, 115.e5-129.e5. doi: 10.1016/j. neuron.2017.09.003

Zhao, L., Teter, B., Morihara, T., Lim, G. P., Ambegaokar, S. S., Ubeda, O. J., et al. (2004). Insulin-degrading enzyme as a downstream target of insulin receptor signaling cascade: implications for Alzheimer's disease intervention. J. Neurosci. 24, 11120-11126. doi: 10.1523/JNEUROSCI.2860-04.2004

Conflict of Interest Statement: The authors declare that the research was conducted in the absence of any commercial or financial relationships that could be construed as a potential conflict of interest. Parts of this manuscript are derived from unpublished material of author's (BJN) $\mathrm{PhD}$ dissertation.

The reviewer OT and handling Editor declared their shared affiliation.

Copyright (C) 2017 Neth and Craft. This is an open-access article distributed under the terms of the Creative Commons Attribution License (CC BY). The use, distribution or reproduction in other forums is permitted, provided the original author(s) or licensor are credited and that the original publication in this journal is cited, in accordance with accepted academic practice. No use, distribution or reproduction is permitted which does not comply with these terms. 